\title{
Shipping risk management practice revisited: a new portfolio approach
}

\section{Article}

\section{Accepted Version}

Creative Commons: Attribution-Noncommercial-No Derivative Works 4.0

Alexandridis, G., Sahoo, S., Song, D.-W. and Visvikis, I. (2018) Shipping risk management practice revisited: a new portfolio approach. Transportation Research Part A, 110. pp. 274-290. ISSN 0965-8564 doi: https://doi.org/10.1016/j.tra.2017.11.014 Available at https://centaur.reading.ac.uk/74099/

It is advisable to refer to the publisher's version if you intend to cite from the work. See Guidance on citing.

To link to this article DOI: http://dx.doi.org/10.1016/j.tra.2017.11.014

Publisher: Elsevier

All outputs in CentAUR are protected by Intellectual Property Rights law, including copyright law. Copyright and IPR is retained by the creators or other copyright holders. Terms and conditions for use of this material are defined in the End User Agreement.

\section{www.reading.ac.uk/centaur}

\section{CentAUR}

Central Archive at the University of Reading

Reading's research outputs online 


\title{
Shipping Risk Management Practice Revisited: A New Portfolio Approach
}

\author{
G. Alexandridis ${ }^{a}$, S. Sahoo ${ }^{a}$ and D-W. Song ${ }^{b} *$, I. Visvikis ${ }^{c}$ \\ (authors are listed in alphabetical order)
}

\begin{abstract}
The international shipping industry is susceptible to heightened market volatility manifested in significant freight rate fluctuations and thus diversifying and hedging the associated risks have become central to shipping business practice. Building on the extant literature on shipping freight derivatives, this study develops a portfolio-based methodological framework aiming to improve freight rate risk management. The study also offers, for the first time, evidence of the hedging performance of the recently developed container freight futures market. Our approach utilises portfolios of container, dry bulk and tanker freight futures along with corresponding portfolios of physical freight rates in order to improve the efficacy of risk diversification for shipping market practitioners. The empirical findings uncovered in this study have important implications for overall business, commercial, and hedging strategies in the shipping industry, while they can ultimately lead to a more liquid and efficient freight futures market.
\end{abstract}

JEL Classification: G11; G31; R40

Keywords: Shipping risk management; Freight derivatives; Portfolio diversification; Hedging effectiveness; Hedge ratios

\footnotetext{
a ICMA Centre, Henley Business School, University of Reading, Whiteknights, Reading, RG6 6BA, UK.

${ }^{\mathbf{b}}$ World Maritime University, Fiskehamnsgatan 1, SE-211 18, Malmö, Sweden.

c American University of Sharjah, School of Business Administration, PO Box 26666, Sharjah, UAE.

* Corresponding Author
} 


\section{Introduction}

One of the fundamental characteristics of the international shipping industry is its distinctively volatile nature which is manifested in significant cash flow and return variability for key shipping market practitioners, such as shipowners, charterers (shippers), operators, and investors, amongst others. Although volatility in vessel prices, bunker fuel prices, foreign exchange and interest rates all contribute towards an environment of heightened uncertainty, freight rate variability is considered as the most important factor amongst all. Accordingly, minimizing freight rate fluctuations - either through utilizing traditional physical market-based diversification with charterparty contracts of different duration or by employing financial hedging strategies with derivatives contracts - has become imperative for shipping businesses. ${ }^{1}$ In this study, we argue that utilizing derivatives contracts over and above holding a welldiversified portfolio of physical freight rates should offer shipping practitioners the opportunity to further minimize their freight rate risk exposures and ultimately lead to superior risk management performance.

Existing studies have examined the performance of hedging strategies involving freight futures in dry bulk markets (see Thuong and Visscher, 1990; Kavussanos and Nomikos, 2000a, b, c; and Kavussanos and Visvikis, 2004; Goulas and Skiadopoulos, 2010) as well as in tanker markets (see Alizadeh et al., 2015a), and point to lower hedging effectiveness (40-60\% variance reduction) relative to what we typically observe in financial and commodity markets. ${ }^{2,3}$ The methodologies employed by previous studies are based on an asset-by-asset framework, whereby each individual (physical) freight rate exposure is hedged against the corresponding (derivatives) futures contract (henceforth referred to as direct hedge). This study employs for the first time, to the best of our knowledge, a portfolio approach that follows a

\footnotetext{
${ }^{1}$ Typically, traditional freight rate risk management involves diversifying holdings in different vessel types (larger vs. smaller) and market sectors (tramp vs. liner), and charterparties of different duration (voyage vs. timecharter) in order to minimize (spread) the risks (see Kavussanos and Visvikis, 2006).

${ }^{2}$ The relatively low hedging performance documented has been primarily attributed to the high basis risk associated with freight futures contracts due to the non-storable nature of the underlying freight service, which allows for no cost-of-carry arbitrage parity trades (see Kavussanos and Nomikos, 2000a and Kavussanos and Visvikis, 2004).

${ }^{3}$ Adland and Jia (2017), for the first time, argue that if freight futures hedge is kept until the settlement (expiration) date, then there is no financial basis risk but rather only physical basis risk from the mismatch between the income stream of the actual vessel and the spot rate index. They argue that this mismatch may be due to technical specifications, deviation in operating speeds and bunker fuel consumption, trading patterns of the global fleet, timing of fixtures and duration of actual trips, and vessel unemployment. Their results indicate that physical basis risk decreases as the fleet size increases and the hedging durations are longer, but it doesn't disappear completely.
} 
modern portfolio theory multi-asset framework in the spirit of Markowitz (1952); ${ }^{4}$ Along these lines, it utilises a mixed portfolio of different freight futures contracts to hedge the price fluctuations of a well-diversified portfolio comprising physical freight rates (henceforth referred to as cross hedge). The main methodological novelty of this portfolio approach is that it considers the correlations and covariances between the freight futures contracts allowing to further reduce the total risk associated with shipping freight markets, thereby improving freight rate risk management. In a recent study, Tsouknidis (2016) finds a strong correlation between freight rates among various shipping segments. In addition, freight rates and corresponding freight futures are typically found tied in long-run equilibrium (cointegrating) relationship, and therefore, spillovers in returns and volatilities within different freight markets have been observed in the dry bulk market (Alexandridis et al., 2017) as well as in the tanker market (Li et al., 2014). This suggests that there may also exist correlations between freight futures contracts corresponding to different physical freight rates. Accordingly, this study takes into account the correlations between a portfolio of physical freight rates and a corresponding portfolio of freight futures contracts to examine the risk management performance of: (i) welldiversified physical freight portfolios, (ii) direct hedge freight futures portfolios, and (iii) cross hedge freight futures portfolios (see Section 2.2 for definitions).

Freight derivative contracts were first introduced in the early 1990s for tramp (dry bulk and tanker) shipping as forward contracts (FFAs - Forward Freight Agreements) traded Over-theCounter (OTC) and tailored to users' needs. More recently, standardized freight forward contracts (henceforth, freight futures contracts) are cleared at various clearing-houses (such as LCH.Clearnet in London, SGX AsiaClear in Singapore, and Nasdaq Clearing in Norway, among others) circumventing counterparty default risk. ${ }^{5}$ The dry bulk Capesize $(160,000$ 180,000 deadweight - dwt vessels), Panamax (74,000 dwt), Supramax (52,000 dwt) and Handysize $(28,000 \mathrm{dwt})$ freight indices quoted in US\$/day or US\$/metric ton, as well as tanker dirty and clean freight indices quoted in Wordscale points or Time-charter Equivalent (TCE), are produced by the Baltic Exchange in London and serve as the underlying assets for the

\footnotetext{
${ }^{4}$ The Modern Portfolio Theory (MPT) as developed by Markowitz (1952) quantifies the diversification of multiple risky assets in portfolios by utilizing the correlations and covariances between the assets to estimate mean (return)-variance (risk) efficient frontiers; that is, set of portfolios which satisfy the condition that no other portfolio exists with a higher expected return at the same level of risk. Past research in diversification of risky assets include Brennan et al. (1997), Cass and Stiglitz (1970) and Roques et al. (2008), among many others. Cullinane (1995) uses the portfolio theory to analyze mean and variances of physical freight rates in dry bulk shipping.

${ }^{5}$ NOS Clearing has merged with NASDAQ OMX in 2014, and the freight derivatives clearing portfolio is managed by NASDAQ Clearing.
} 
corresponding dry bulk and tanker futures, respectively. ${ }^{6}$ Such freight indices accurately reflect current market conditions as they are estimated from the average freight rates quotations provided by a panel of international shipbrokers (the Panellists) appointed by the Baltic Exchange. Freight futures contracts are cash-settled contracts between an agreed futures price and a settlement price which is calculated as the average of the underlying physical freight rates during all business days of the maturity (settlement) month. ${ }^{7}$

Further, the typically oligopolistic liner (container) shipping market, started exhibiting perfect competition characteristics after the abolition of liner (price fixing) conferences in 2008, exposing the liner companies and shippers to significant freight rate volatilities. The Container Swap Forward Agreements (CFSA) contracts started trading OTC in 2010, through freight derivatives brokers, and are settled against the 15 freight routes of the Shanghai Containership Freight Index (SCFI) provided by the Shanghai Shipping Exchange (SSE). They are quoted as US\$/TEU (Twenty-foot Equivalent Unit) or US\$/FEU (Forty-foot Equivalent Unit). For the purpose of eliminating counterparty (credit) risk these contracts are cleared in the SGX AsiaClear clearing house. Our study employs for the first time a sample that includes container derivatives, therefore, providing new evidence of hedging performance within this emerging market of the shipping industry. Such markets have long posed a challenge for financial research. More specifically, Kavussanos et al. (2008) report that "emerging market returns are characterised by low liquidity, thin trading, higher sample averages, low correlations with developed market returns, non-normality, better predictability, higher volatility and short samples. In addition, market imperfections, high transaction and insurance costs, less informed rational traders and investment constraints may also affect the risks and returns involved" (see also Kavussanos and Visvikis, 2008). Thus, emerging market returns can exhibit different characteristics to those in developed markets, making the empirical investigation of the rather illiquid container FFA market important in terms of offering valuable insights (for a detailed

\footnotetext{
${ }^{6}$ Worldscale rates are estimated assuming that a "nominal" tanker exists on round voyages between assigned ports. The Baltic exchange was established in 1883 in London to establish an organised market for market practitioners that wish to buy and sell freight services (for more details, see Kavussanos and Visvikis, 2006).

${ }^{7}$ An example of how they are used in practice is the following: if a shipowner (charterer) sells (buys) one contract of Capesize Time-Charter (T/C) futures at US $\$ 8,000 /$ day on $1^{\text {st }}$ March 2016, with a settlement of US\$7,000/day on $31^{\text {st }}$ May 2016, the shipowner (charterer) would gain (loss) US $\$ 1,000$ in the freight derivatives positon, which will then be used to cover the loss (profit) of the underlying freight rate position.
} 
discussion on the special features of emerging markets see Bakaert and Harvey, 1997; and Antoniou and Ergul, 1997). ${ }^{8}$

To implement our portfolio approach, we first derive a well-diversified freight rate portfolio, where the weights of individual assets are optimized using Markowitz's risk-return theory and compare it with an undiversified freight rate portfolio, where the weights of individual assets are identical, for seven different physical freight rate route scenarios involving the following: (a) dry bulk - Capesize, Panamax and Supramax time-charter rates; (b) tanker - TD3 (Middle East Gulf to Japan) and TC2 (Europe to US Atlantic Coast) route voyage rates; and (c) container - Shanghai to US West Coast (USWC) and Shanghai to North West Europe (NWE) spot rates, and then we measure the degree of variance reduction and utility increase due to portfolio diversification. As a second step, we extend our analysis and use direct hedge and cross hedge freight futures portfolios (as defined in Section 2.2) to hedge the well-diversified (optimal) freight rate portfolio. We then measure the additional (to the physical freight rate diversification) variance reduction and utility increase stemming from financial hedging with derivatives contracts.

Along these lines, Johnson (1960) and Stein (1961) use an MPT framework to estimate the weights of futures contracts required per unit weight of underlying physical assets to obtain a minimum variance portfolio. This ratio of futures contracts weights corresponding to unit weights of physical assets is referred to as the Minimum Variance Hedge Ratio (MVHR), while the variance reduction or the utility increase of the unhedged physical position to the hedged futures position is the hedging effectiveness. ${ }^{9}$ Ederington (1979) and Franckle (1980) applies this framework to examine the hedging performance of futures contracts written on US T-Bills. Subsequently, Figlewski (1984), Figlewski (1985) and Lindahl (1992), amongst others, estimate optimal hedge ratios and corresponding hedging performances for stock index futures. Furthermore, we estimate and compare various constant and time-varying (dynamic) hedge ratio models both in-sample and out-of-sample. In-sample tests are mainly based on past (historical) information, while the out-of-sample performance of hedge ratios is more relevant to practitioners (see Kavussanos and Visvikis, 2008). It has been documented in the literature

\footnotetext{
${ }^{8}$ Given the relatively low trading volume of container derivatives in the most recent years of our sample we have also repeated our analysis by excluding this segment completely and find quantitatively similar results in terms of the improvement in risk minimisation (see Section 2.4).

${ }^{9}$ Detail estimations of MVHR and the variance reduction measure are presented in Section 2.
} 
that dynamic hedge ratio models tend to outperform constant ones in foreign exchange and agriculture commodity futures markets (see Kroner and Sultan, 1993; and Bera et al., 1997), whereas the opposite holds in live cattle futures markets (see McNew and Fackler, 1994).

Our results indicate that the portfolio diversification reduces freight rate fluctuations up to $35 \%$ for mixed portfolios of container, dry bulk and tanker freight rate routes. Furthermore, results from using freight futures contracts on a portfolio approach point to a further freight rate risk reduction up to a $23 \%$. The constant hedge ratio models seem to outperform time-varying ones in most examined cases both in-sample and out-of-sample, indicating that the risk minimisation positions do not need to be updated when new information arrives in the market.

This study contributes to the existing literature on freight rate risk management as follows. First, it is the first study to examine optimal hedge ratios for all three major shipping subsectors; namely, the dry bulk, tanker and the newly developing container futures. Our results offer new insights on the effectiveness of financial risk management practices in the container sector, which could ultimately result in alleviating transportation costs for consumer goods carried in containers, thereby reducing the cost for the end consumer (Tsai et al., 2011). Second, we utilize mixed portfolios of container, dry bulk and tanker freight futures along with corresponding well-diversified portfolios of physical freight rates in order to further improve the efficacy of risk minimization for shipping market practitioners. Our results corroborate that utilizing a mixed portfolio (cross hedge) of futures contracts significantly decrease freight rate risk relative to well-diversified portfolios of physical freight rates, contributing to existing research on shipping risk management. The documented hedging performance improvements have important implications for overall business, operating, and chartering strategies in the shipping industry, while they can ultimately result in more liquid and efficient freight futures markets.

The remaining of the study is organized as follows: Section 2 develops the theoretical framework and presents the methodology used to estimate the direct hedge and cross hedge portfolios based on various scenarios. The data and preliminary analysis are presented in Section 3. Section 4 presents the empirical results. Section 5 concludes the study. 


\section{Theoretical Framework and Methodology}

\subsection{Minimum Variance and Utility Maximizing Hedge Ratios}

A shipowner (charterer) can hedge a short (long) position in the physical freight market by taking a long (short) position in the freight futures market. Thus, a loss (gain) in the physical freight market can be offset by a gain (loss) in the futures market. Equation (1) represents the freight return generated by a portfolio comprising of physical freight rates and freight futures contracts and Equation (2) represents the variance of the corresponding portfolio return:

$$
\begin{aligned}
R_{H, t}=\Delta S_{t} & -\gamma_{t} \Delta F_{t} \\
\operatorname{Var}_{t}\left(R_{H, t}\right) & =\operatorname{Var}_{t}\left(\Delta S_{t}-\gamma_{t} \Delta F_{t}\right) \\
& =\operatorname{Var}_{t}\left(\Delta S_{t}\right)+\gamma_{t}^{2} \operatorname{Var}_{t}\left(\Delta F_{t}\right)-2 \gamma_{t} \operatorname{Cov}_{t}\left(\Delta S_{t}, \Delta F_{t}\right)
\end{aligned}
$$

where, $R_{H, t}$ represents the conditional return of the hedged portfolio $(H) ; \Delta S_{t}=S_{t}-S_{t-1}$ represents the logarithmic change in freight rates between time periods $t-1$ and $t ; \Delta F_{t}=$ $F_{t}-F_{t-1}$ represents the logarithmic change in futures prices between time periods $t-1$ and $t$; and $\gamma_{t}$ is the hedge ratio expressed as the value of freight futures contracts over the value of the underlying freight rate exposure at time $(t)$. In Equation (2), $\operatorname{Var}_{t}\left(R_{H, t}\right)$ is the variance of the return of the hedged portfolio $\left(R_{H, t}\right)$ as defined in Equation (1). $\operatorname{Var}_{t}\left(\Delta S_{t}\right)$ and $\operatorname{Var}_{t}\left(\Delta F_{t}\right)$ are the conditional variances of underlying freight rates and freight futures returns, respectively; and $\operatorname{Cov}_{t}\left(\Delta S_{t}, \Delta F_{t}\right)$ is the covariance of freight rates and freight futures returns.

When $\gamma_{t}=0$, the physical freight rate position remains completely unhedged, while when $\gamma_{t}=1$, the futures position is equal in magnitude, but opposite in direction, to the freight rate exposure. This so-called "nä̈ve" (one-to-one) hedge ratio provides a perfect hedge only if the freight rates and the freight futures prices are perfectly correlated, and the risks (variances) of each of the two markets are equal. In practice, however, given the presence of market frictions, the variabilities of freight futures prices and their underlying freight rates are not the same, and therefore, they do not involve the same level of risk. Thus, in reality, the estimated hedge ratios are typically different from unity.

The Minimum Variance Hedge Ratio (MVHR) is estimated by minimizing the variance of the hedged portfolio, $\operatorname{Var}_{t}\left(R_{H, t}\right)$ from Equation (2): 


$$
\frac{\partial\left[\operatorname{Var}_{t}\left(R_{H, t}\right)\right]}{\partial\left[\gamma_{t}\right]}=0
$$

Substituting the value of $\operatorname{Var}_{t}\left(R_{H, t}\right)$ from Equation (2):

$$
2 \gamma_{t} \operatorname{Var}_{t}\left(\Delta F_{t}\right)-2 \operatorname{Cov}_{t}\left(\Delta S_{t}, \Delta F_{t}\right)=0
$$

Solving for $\gamma_{t}$ :

$$
\gamma_{t}^{*}=\frac{\operatorname{Cov}_{t}\left(\Delta S_{t}, \Delta F_{t}\right)}{\operatorname{Var}_{t}\left(\Delta F_{t}\right)}=\rho_{(\Delta S)(\Delta F), t} \frac{\sigma_{(\Delta S), t}}{\sigma_{(\Delta F), t}}
$$

where, $\gamma_{t}^{*}$ is the MVHR which corresponds to the minimum value of the variance of the hedged portfolio, $\operatorname{Var}_{t}\left(R_{H, t}\right) ; \rho_{(\Delta S)(\Delta F), t}$ is the correlation coefficient between the freight rate returns $(\Delta S)$ and the futures returns $(\Delta F)$, while $\sigma_{(\Delta S), t}$ and $\sigma_{(\Delta F), t}$ are the respective standard deviations.

A highly risk averse market practitioner would typically prefer to eliminate as much risk as possible by taking a futures position that generates relatively lower returns. In contrast risk seeking practitioner would prefer to maximize her return at the expense of bearing more risk. Most market practitioners can be broadly categorized in terms of risk aversion within the range of these two extreme cases. Therefore, it is necessary to consider the practitioners' degree of risk aversion when estimating the corresponding optimal hedge ratio that maximizes the expected utility, $E_{t} U\left(R_{H, t+1}\right)$ of the hedged portfolio at any given point in time, $t$. Consider the following mean-variance expected utility function:

$$
E_{t} U\left(R_{H, t+1}\right)=E_{t}\left(R_{H, t+1}\right)-k \operatorname{Var}_{t}\left(R_{H, t+1}\right)
$$

where, $k$ is the coefficient of risk aversion indicating the degree of risk of a given individual practitioner; that is, a higher (lower) value of $k$ indicates a higher (lower) risk aversion. ${ }^{10}$ The formula assumes a quadratic utility function and the portfolio return is normally distributed according to the Markowitz (1968) framework (see Levy and Markowitz, 1979 for more details on the quadratic utility function).

\footnotetext{
${ }^{10} k$ being infinite and zero indicates pure risk averse and pure risk seeking practitioners, respectively.
} 
The expected utility function $E_{t} U\left(R_{H, t+1}\right)$ from Equation (4), by varying the hedge ratio $\left(\gamma_{t}\right)$, the Utility Maximizing Hedge Ratio (UMHR - $y_{t}^{* *}$ ) is estimated as follows:

$$
\frac{\partial\left[E_{t} U\left(R_{H, t+1}\right)\right]}{\partial\left[\gamma_{t}\right]}=0
$$

Substituting the value of $E_{t} U\left(R_{H, t+1}\right)$ from Equation (4):

$$
\frac{\partial\left[E_{t}\left(R_{H, t+1}\right)\right]}{\partial\left[\gamma_{t}\right]}-\frac{\partial\left[k \operatorname{Var}_{t}\left(R_{H, t+1}\right)\right]}{\partial\left[\gamma_{t}\right]}=0
$$

From Equation (1) and (2):

$$
\begin{aligned}
& -\Delta F_{t+1}-2 k \gamma_{t} \operatorname{Var}_{t}\left(\Delta F_{t+1}\right)+2 k \operatorname{Cov}_{t}\left(\Delta S_{t+1}, \Delta F_{t+1}\right)=0 \\
& \gamma_{t}=\frac{\operatorname{Cov}_{t}\left(\Delta S_{t+1}, \Delta F_{t+1}\right)}{\operatorname{Var}_{t}\left(\Delta F_{t+1}\right)}-\frac{\Delta F_{t+1}}{2 k \operatorname{Var}_{t}\left(\Delta F_{t+1}\right)}
\end{aligned}
$$

From Equation (3):

$$
y_{t}^{* *}=\gamma_{t}^{*}+\left[\frac{-\Delta F_{t+1}}{2 \operatorname{kVar}_{t}\left(\Delta F_{t+1}\right)}\right]=\gamma_{t}^{*}+\left[\frac{-\operatorname{Bias}_{t+1}}{2 k \operatorname{Var}_{t}\left(\Delta F_{t+1}\right)}\right]
$$

where, Bias $_{t+1}=E_{t}\left(\Delta F_{t+1}\right)=E_{t}\left(F_{t+1}\right)-F_{t}$ represents the bias in futures prices between periods $t$ and $t+1$. The $\mathrm{UMHR}\left(y_{t}^{* *}\right)$ in Equation (5) has two components; the first component is a pure hedging component derived from Equation (3); the $\operatorname{MVHR}\left(\gamma_{t}^{*}\right)$. The second component is a speculative component, which depends on the risk aversion of the individual practitioner and the efficiency level of the futures market (see Kavussanos and Visvikis, 2008 for more details). There are two cases to consider:

Case 1: If the coefficient of risk aversion is very large, the speculative component in Equation (5) will be negligible. Hence, for a highly risk averse practitioner the MVHR is equal to the UMHR. This indicates that market practitioners are not concerned about higher returns, but are rather only interested in minimizing the variance of their portfolios. So, the utility function from Equation (4) is not relevant for highly risk averse practitioners.

Case 2: If the futures returns follow a martingale process, that is, futures prices are unbiased and the risk averse coefficient $(k)$ is finite, the second term in Equation (5) will not be 
significantly different from zero. ${ }^{11}$ This implies that the speculative positions using futures contracts will have an equal probability of generating profits and losses. This case arises in an efficient market where the returns of the futures contract follow a stochastic process with no deterministic trend. For these types of cases $y_{t}^{*}=\gamma_{t}^{* *}$; that is, the MVHR is also equal to the UMHR. The futures markets constitute of both deterministic and stochastic components. Practitioners use the price biasness generated from the deterministic component of the futures markets to develop various investment/speculative strategies.

\subsection{Freight Route Scenarios and Portfolio Formation}

In practice, shipping practitioners typically trade in more than one risky asset class (i.e. a mix of freight routes that correspond to different vessel types) and hence are exposed to various freight rate risks. In addition, individual market practitioners have various advantages in operating in particular sectors of the shipping industry, following their experience in maritime operations of vessels and/or as part of their business strategy. Thus, besides following the market fundamentals to diversify their freight rate portfolio, they also follow their competitive advantages for choosing the weights of particular market sectors and/or types of vessels. This creates infinite possible combinations of freight rates, which in practice, makes the exact calculation of all the efficient portfolios difficult to establish. However, to institute a practical approach of freight rate diversification, we have considered that, if a shipping practitioner is operating a specific portfolio of freight rates (say, tanker and dry bulk), then she has an equal competitive advantage in each of the used freight markets (that is, tanker and dry bulk). For the sake of brevity, the numerous freight rate portfolio weights combinations are not presented in the paper, but are available upon request. So, a traditional hedging strategy is developed utilizing a mean-variance portfolio framework to estimate optimal weights for each risky freight rate in the physical portfolio, generating an efficient frontier well-diversified portfolio. A financial risk management strategy is then formulated to hedge this well-diversified portfolio of freight rates by taking positions in multiple futures contracts, capturing the correlations and covariance between them, and therefore, minimising risk more effectively. To this end, we employ various freight rate route scenarios to account for wide range of shipping market practitioners with different physical freight rate exposures:

\footnotetext{
${ }^{11}$ A martingale process is a process in which the conditional expectation of the price next period is equal to the price in the current period, given knowledge of all past observed prices.
} 
Base Scenario - A freight rate portfolio with all three major sub-sectors; that is, container (NWE \& USWC), dry bulk (Capesize, Panamax and Supramax) and tanker (TC2 and TD3) freight routes. In this scenario, the efficient frontier is derived using the returns generated from all seven freight rate routes; Scenario 1 - Container (NWE \& USWC) and dry bulk (Capesize, Panamax and Supramax) freight rate routes; Scenario 2 - Dry bulk (Capesize, Panamax and Supramax) and tanker (TC2 and TD3) freight rate routes; Scenario 3 - Tanker (TC2 and TD3) and container (NWE \& USWC) freight rate routes; Scenario 4 - Only container (NWE \& USWC) freight rate routes; Scenario 5 - Only dry bulk (Capesize, Panamax and Supramax) freight rate routes; and Scenario 6 - Only tanker (TC2 and TD3) freight rate routes.

The following portfolios are then formed for each of the above seven freight rate route scenarios:

Portfolio 1 - Well-diversified physical freight rate portfolio: An efficient frontier is estimated only with risky physical freight rates, based on the following constraints:

Constraint A - No Short Positions: The participant is only allowed to hold positive weights on the freight rate returns. For example, this prevents a shipowner from becoming a charterer (and vice versa):

$$
W_{s, i} \geq 0(\text { for } \forall i)
$$

Constraint B - Total Investment: The sum of all the weights of the freight rate returns is equal to one, indicating that that the shipowner intends to generate her entire profit from shipping operations by chartering out vessels: ${ }^{12}$

$$
\sum_{i=1}^{n} W_{s, i}=1(\text { where } n=\text { number of freight rates to hedge })
$$

The return and variance of the well-diversified portfolio of freight rates are determined as follows:

$$
\begin{aligned}
& R_{W D}=\omega_{s}^{\prime} R_{s} \\
& \sigma_{W D}^{2}=\omega_{s}^{\prime} V \omega_{s}
\end{aligned}
$$

\footnotetext{
12 This restrictive assumption is taken on purpose to isolate the risks and returns only to freight rates. Relaxing the assumption allows for the inclusion of risks from positions in other assets in shipping or from positions in other industry sectors, but this is left for future research.
} 
where, $\omega_{s}=\left(\omega_{s, 1} \omega_{s, 2} \ldots \omega_{s, n}\right)^{\prime}$ is an $(n \times 1)$ vector of the portfolio proportions, such that $\omega_{s, i}$ is the proportion of freight rate return for $i^{t h}$ vessel type; $R_{S}=\left(R_{s, 1} R_{s, 2} \ldots R_{s, n}\right)^{\prime}$ is a $(n \times 1)$ vector of the expected freight rate returns; and $V$ is a $(n \times n)$ covariance matrix, which is also symmetric and positive definite. In our study, $n=7$ since we consider seven different freight rate route scenarios.

Portfolio 2 - Direct hedge freight futures portfolio: This is the typical futures hedging model, where futures contracts are used to minimize the variance of the corresponding physical freight rate exposures. The MVHR is estimated from Equation (3) to determine the weights of the freight futures contracts for hedging the well-diversified freight rate portfolio. Along with the two constraints (Constrain A and B) used in the well-diversified (unhedged) portfolio (Portfolio 1), there is one additional constraint for obtaining the weights of the direct hedge portfolio:

Constraint $\boldsymbol{C}$ - Futures Weight Ratio: The weight of the futures contracts is the product of the weight of the corresponding freight rates and MVHR:

$$
\omega_{f, i}=\gamma_{t, i}^{*} \times \omega_{s, i}
$$

where, $\gamma_{t, i}^{*}$ is the MVHR for a freight rate $i$ that is calculated from Equation (3); and $\omega_{f, i}$ refers to the weight of freight futures contracts used to hedge the freight rate exposure. The return and variance of the direct hedge portfolio are determined as follows:

$$
\begin{aligned}
& R_{D H}=\omega_{T}^{\prime} R_{T} \\
& \sigma_{D H}^{2}=\omega_{T}^{\prime} V \omega_{T}
\end{aligned}
$$

where, $R_{T}=\left(R_{s, 1} R_{s, 2} \ldots R_{s, n} R_{f, 1} R_{f, 2} \ldots R_{f, n}\right)^{\prime}$ is a $(2 n \times 1)$ vector of the returns of $n$ freight rates and $n$ futures contracts; $V$ is a $(2 n \times 2 n)$ covariance matrix of returns of $n$ freight rates and $n$ futures contracts that is also symmetric and positive definite; $\omega_{T}=$ $\left(\omega_{s, 1} \omega_{s, 2} \ldots \omega_{s, n} \omega_{f, 1} \omega_{f, 2} \ldots \omega_{f, n}\right)^{\prime}$ is a $(2 n \times 1)$ vector of the portfolio proportions, such that $\omega_{s, i}$ is the weight of $i^{t h}$ freight rate determined in the well-diversified portfolio, $\omega_{f, i}$ is the weight of $i^{\text {th }}$ futures contracts traded (short position) by the shipowner to hedge the freight rate exposure, while $\omega_{f, i}$ is determined using Constraint $\mathrm{C}$.

Portfolio 3 - Cross hedge freight futures portfolio: A cross hedge solution is introduced where the multi-freight rate exposures are hedged using multiple freight futures contracts; that is, hedging freight rate $i$ using freight futures $j$, for all values of $i$ and $j$. The sets of portfolios are 
optimized to minimize the risks (variance) of the returns generated from both physical freight rates and freight futures contracts. Along with the first two constraints (Constrain A and B) used in the well-diversified portfolio (Portfolio 2), one additional constraint exists when obtaining the weights of the cross hedge portfolio:

Constraint D - Short Futures Position: The shipowner is only allowed to act as a hedger and can only take short (sell) positions in freight futures contracts (speculation is not allowed):

$$
W_{f, j} \leq 0(\text { for } \forall j)
$$

The return and variance of the cross hedge portfolio are determined as follows:

$$
\begin{aligned}
& R_{C H}=\omega_{T}^{\prime} R_{T} \\
& \sigma_{C H}^{2}=\omega_{T}^{\prime} V \omega_{T}
\end{aligned}
$$

where, $R_{T}=\left(R_{s, 1} R_{s, 2} \ldots R_{s, n} R_{f, 1} R_{f, 2} \ldots R_{f, n}\right)^{\prime}$ is a $(2 n \times 1)$ vector of the returns of $n$ futures contracts used to hedge $n$ freight rate exposures; $V$ is the $(2 n \times 2 n)$ covariance matrix of returns of $n$ freight rates and $n$ futures contracts that is also symmetric and positive definite; $\omega_{T}=\left(\omega_{s, 1} \omega_{s, 2} \ldots \omega_{s, n} \omega_{f, 1} \omega_{f, 2} \ldots \omega_{f, n}\right)^{\prime}$ be a $(2 n \times 1)$ vector of the portfolio proportions, such that $\omega_{s, i}$ is the proportion of weights of $i^{\text {th }}$ freight rate determined in the well-diversified portfolio of freight rates and $\omega_{f, i}$ is the weight of $i^{\text {th }}$ futures contracts traded (short position) by shipowner to hedge the freight rate fluctuations.

\subsection{Estimation of Optimal Hedge Ratios}

The coefficient of $\Delta F_{t}$ (slope coefficient) is used to estimate the conventional (constant) MVHR for direct hedge and cross hedge portfolios in the following Ordinary Least Squares (OLS) regression:

$$
\Delta S_{t}=h_{0}+\gamma^{*} \Delta F_{t}+\varepsilon_{t}, \quad \quad \varepsilon_{t} \sim \operatorname{iid}\left(0, \sigma^{2}\right)
$$

A potential issue that arises with the constant MVHR is that it fails to capture the time-varying distributions of freight rates and futures prices. In addition, if cointegration exist between freight rates $\left(S_{t}\right)$ and futures prices $\left(F_{t}\right)$, an Error-correction term (ECT) should be added to the Equation (6) since neglecting it, leads to an omitted variable problem, resulting in a biased coefficient $\gamma^{*}$ (Kroner and Sultan 1993). Finally, the price discovery function in derivatives markets suggests that there should be is a strong information transmission flow from the freight 
futures market $\left(\Delta F_{t}\right)$ to the freight rate market $\left(\Delta S_{t}\right)$ (see Kavussanos and Visvikis, 2004). However, Alexandridis et al. (2017) argue that there is also a weak information feedback from freight rates to the freight futures markets, which could potentially create an endogeneity problem. The potential omitted variable biasness and the endogeneity problem can be both mitigated by using a bivariate Vector-Error Correction Model (VECM) to estimate $\gamma_{t}^{*}$, where the explained variable is regressed against the ECT and lags of the explanatory variable. If freight rates $\left(S_{t}\right)$ and freight futures $\left(F_{t}\right)$ are non-stationary variables then there may exist a long-run equilibrium cointegration relationship between them. In such case, the Johansen (1988) test is used to determine whether a cointegrating vector exists with a linear combination of freight rate and freight futures prices. If no long-run relationship between the two series is present, the ECT term from Equation (7) is omitted and a Vector Autoregressive (VAR) model is estimated instead.

The VECM constant MVHR $\left(y_{t}^{*}\right)$ in Equation (7) is computed as the ratio of the covariance of the error-terms of freight rates and freight futures returns $\left(\operatorname{Cov}\left(\varepsilon_{S, t}, \varepsilon_{F, t}\right)\right)$ over the variance of the error-term of the futures return $\left(\operatorname{Var}\left(\varepsilon_{F, t}\right)\right)$ :

$$
\gamma_{t}^{*}=\frac{\operatorname{Cov}\left(\varepsilon_{S, t}, \varepsilon_{F, t}\right)}{\operatorname{Var}\left(\varepsilon_{F, t}\right)}=\frac{\sigma_{S, F, t}}{\sigma_{F, t}^{2}}
$$

Time-varying conditional distributions of freight rates and freight futures returns are used to compute dynamic (time-varying) optimal hedge ratios. As participants are interested in the outof- sample performance of the model, a one-step ahead hedge ratio is estimated as follows:

$$
\gamma_{t+1}^{*} \mid \Omega_{t}=\frac{\operatorname{Cov}\left(\varepsilon_{S, t+1}, \varepsilon_{F, t+1}\right)}{\operatorname{Var}\left(\varepsilon_{F, t+1}\right)}=\frac{\sigma_{S, F, t+1}}{\sigma_{F, t+1}^{2}}
$$

where, the MVHR for one period ahead $\left(\gamma_{t+1}^{*}\right)$ is estimated from all the information available at the present time $\left(\Omega_{t}\right)$. The variance-covariance matrix $(H)$ of error-terms from the bivariate VECM in Equation (13) becomes time-varying $\left(H_{t}\right)$ following a Generalized Autoregressive Conditional Heteroscedasticity (GARCH) framework (Bollerslev, 1987). Similar conditional variance approaches on error-terms are used by Park and Switzer (1995) and Kroner and Sultan (1993), amongst others, to estimate time-varying optimal hedge ratios. Following the estimations of the VAR- (or VECM-) GARCH model, time-varying covariances and variances are used to calculate MVHRs. The UMHRs can be estimated using the Bias $_{t+1}$ and $\operatorname{Var}_{t}\left(P F_{m, t+1}\right)$ along with the MVHRs as in Equation (5). The optimal weights for the cross 
hedge portfolio are estimated using a nonlinear convex optimization technique (see Tuy et al., 1998; and Bertsekas et al., 2003 for more details) to minimize the total risks (variance) associated with the freight rate and freight futures returns.

\subsection{Evaluation of Portfolio Performance}

In this section, we present the criteria used to evaluate the performance of the various models. Further, a comparative analysis is conducted to select the most effective model.

\subsubsection{Performance of well-diversified portfolio of freight rates}

We compare an equally weighted (undiversified) portfolio of freight rates with the estimated well-diversified portfolio of freight rates which maximize the return for each level of risk. The portfolio performance is measured as the percentage variance reduction $(V R)$ of the welldiversified portfolio of freight rates over and above the equally weighted portfolio of freight rates: $:^{13}$

$$
V R_{W D_{-} E W}=\frac{\operatorname{Var}\left(R_{E W}\right)-\operatorname{Var}\left(R_{W D}\right)}{\operatorname{Var}\left(R_{E W}\right)} \times 100
$$

where, $\operatorname{Var}\left(R_{E W}\right)$ and $\operatorname{Var}\left(R_{W D}\right)$ represent the variance of the equally weighted and welldiversified portfolio returns, respectively. A higher $V R$ corresponds to greater diversification performance.

\subsubsection{Performance of direct hedge using freight futures}

Various alternative constant and time-varying hedge ratio specifications are estimated to evaluate the hedging performance of the direct hedging portfolio corresponding to MVHRs and UMHRs. ${ }^{14}$ For each of the vessel-type sub-sectors, three different hedge ratios are estimated; that is, two constant hedge ratios are estimated from OLS and VECM models, while a time-varying hedge ratio is estimated from a VECM-GARCH model. In addition to the three computed hedge ratios for each sub-sector, a naïve hedge ratio is also used as a benchmark,

\footnotetext{
${ }^{13}$ The variance of the global minimum variance portfolio is used against the equally weighted portfolio, as a welldiversified portfolio can provide various sets of portfolios producing different returns at different level of risks. As the $V R$ measure aims to minimize the risk of exposure, we have considered the global minimum variance portfolio as a measure to estimate the decrease in variance due to diversification.

${ }^{14}$ If the freight rates corresponding to freight futures returns are time-varying, then the optimal hedge ratio needs to be periodically (say, weekly or monthly) adjusted with new information arriving in the market.
} 
where the hedge ratio is equal to one $\left(\gamma_{t}^{*}=1\right)$. The following two measures are used to estimate the hedging effectiveness of the various models:

Variance Reduction $(V R)$ : This measure compares the reduction of the variance of the hedged portfolio $\left(\operatorname{Var}\left(R_{H, t}\right)\right)$ over the variance of unhedged portfolio, $\left(\operatorname{Var}\left(\Delta S_{t}\right)\right)$ as follows:

$$
V R=\frac{\operatorname{Var}\left(\Delta S_{t}\right)-\operatorname{Var}\left(R_{H, t}\right)}{\operatorname{Var}\left(\Delta S_{t}\right)} \times 100
$$

Between the alternative competing models, the one with the highest $V R$ is the one with the highest hedging effectiveness. For the OLS model, the $V R$ of the hedged portfolio is computed by the coefficient of determination $\left(R^{2}\right)$ of the OLS regression; that is, the higher the $R^{2}$ the greater the hedging effectiveness.

Utility Increase (UI): This measure considers the hedger's risk averse attitude through a utility function, as in Equation (4). Consider the following utility increase equation:

$$
U I=E_{t} U\left(R_{H, t+1}\right)-E_{t} U\left(\Delta S_{t+1}\right)
$$

The model with the higher $U I$ has the greater performance at a certain level of risk. The $V R$ and $U I$ measures are used to determine which of the models are more suitable for reducing risk and increasing utility from hedging, respectively.

\subsubsection{Performance of cross hedge using freight futures}

The model with highest hedging effectiveness estimated from the direct hedge portfolio is utilized to generate a portfolio comprising of all seven different freight futures as well as the corresponding physical freight rates. Restrictions on freight rates are imposed in all scenarios, as discussed above. The performance of the cross hedge portfolio is evaluated using both the $V R$ and $U I$ criteria as follows:

Variance Reduction $(V R)$ : The variance of the cross hedge portfolio return, $\operatorname{Var}\left(R_{C H}\right)$, is compared with the variance of the well-diversified portfolio, $\operatorname{Var}\left(R_{W D}\right)$ using:

$$
V R_{C H_{-} W D}=\frac{\operatorname{Var}\left(R_{W D}\right)-\operatorname{Var}\left(R_{C H}\right)}{\operatorname{Var}\left(R_{W D}\right)} \times 100
$$

where, the variances of returns are estimated for both the cross hedge and the well-diversified portfolios for the various scenarios. If $V R_{C H_{-} W D}$ is positive - the variance of cross hedge portfolio is lower than well-diversified portfolio - then this indicates that the cross hedge 
outperforms the well-diversified portfolio. A higher hedging performance of the cross hedge portfolio would be reflected in a higher $V R_{C H_{-} W D}$.

Utility Increase (UI): The expected utility increase of the cross hedge portfolio return over and above the well-diversified portfolio return indicates an increase in the satisfaction level due to holding the cross hedge portfolio, as compared to only holding the well-diversified portfolio:

$$
U I_{C H_{-} W D}=E_{t}\left[U\left(R_{C H, t+1}\right)\right]-E_{t}\left[U\left(R_{W D, t+1}\right)\right]
$$

A higher level of satisfaction corresponds to a higher $U I$ level $\left(U I_{C H \_W D}\right)$.

\subsubsection{Comparative analysis of performance: Direct hedge vs. Cross hedge}

The VR and UI of the direct hedge portfolio are estimated with respect to the well-diversified portfolio using Equation (19) and (20), respectively:

$$
\begin{aligned}
& V R_{D H_{-} W D}=\frac{\operatorname{Var}\left(R_{W D}\right)-\operatorname{Var}\left(R_{D H}\right)}{\operatorname{Var}\left(R_{W D}\right)} \times 100 \\
& U I_{D H_{-} W D}=E_{t}\left[U\left(R_{D H, t+1}\right)\right]-E_{t}\left[U\left(R_{W D, t+1}\right)\right]
\end{aligned}
$$

where, $V R_{D H_{-} W D}$ and $U I_{D H_{-} W D}$ represent the $V R$ and $U I$ of the direct hedge portfolio, respectively. The direct hedge portfolio $\left(P_{D H}\right)$ of futures contracts is formed by applying Constrain $\mathrm{C}$ on the well-diversified portfolio $\left(P_{W D}\right)$ of freight rates. Finally, the VR and $U I$ of the cross hedge portfolio with respect to the direct hedge portfolio are obtained using Equations (21) and (22), respectively:

$$
\begin{gathered}
V R_{C H_{-} D H}=\frac{\operatorname{Var}\left(R_{D H}\right)-\operatorname{Var}\left(R_{C H}\right)}{\operatorname{Var}\left(R_{D H}\right)} \times 100 \\
(21) \\
U I_{C H_{-} D H}=E_{t}\left[U\left(R_{C H, t+1}\right)\right]-E_{t}\left[U\left(R_{D H, t+1}\right)\right]
\end{gathered}
$$

Positive $V R_{C_{-} H_{-} H}$ and $U I_{C_{-} H_{-} D}$ would indicate that the cross hedge portfolio outperforms the direct hedge portfolio.

\section{Data Description}

This study utilizes weekly (Friday) closing prices of physical freight rates for: (i) Shanghai North West Europe (NWE) and Shanghai - US West Coast (USWC) container SCFI routes of SSE, as reported by Clarksons Shipping Intelligence Network; (ii) Time-Charter Equivalent 
(TCE) rates for Capesize, Panamax and Supramax dry bulk vessels, as reported by the Baltic Exchange; and (iii) Rotterdam - US East Coast (TC2) and Middle East - Japan (TD3) tanker routes, as reported by the Baltic Exchange. ${ }^{15}$ Those freight rate routes are selected as they are the most liquid in terms of trading in the three shipping sub-sectors. Corresponding weekly (Friday) freight futures prices are used for the aforementioned freight routes: Container derivatives prices are provided by LCH.Clearnet and Freight Investor Services (FIS), while dry bulk and tanker futures prices are provided by the Baltic Exchange. ${ }^{16}$

A total of 263 weekly observations, from February 2011 to June 2016 are used for all three sub-sectors. In case a holiday occurs on Friday, then the Thursday observation is used instead. ${ }^{17}$ Rolling near-month and second near-month maturity freight futures contracts are used in the ensuing analysis. ${ }^{18}$ All prices are transformed into natural logarithms. The choice of a weekly data frequency is justified by the fact that it is not very realistic in practice to rebalance hedge positions on a daily basis, due to excessively high transaction costs. ${ }^{19}$ Further, as freight futures contracts suffer from liquidity, bid-ask spreads tend to be relatively high, and as such, daily repositioning of the hedge positions are found to be not cost effective (Alizadeh et al., 2015b). The weekly hedge frequency is also in accordance with the past literature (Kavussanos and Nomikos, 2000a; and Kavussanos and Visvikis, 2010).

This study uses three different types of freight rates to create a physical well-diversified portfolio; that is, dry bulk time-charter rates (quoted in US\$/day), tanker voyage charter rates (quoted in US\$/tonne) and container spot charter rates (quoted in US\$/TEU). The choice of freight rates in each sector (say dry bulk, tanker and container) are based on the liquidity of

\footnotetext{
15 The choice of Friday observations is due to the restriction of reporting of container data, as SSE produces the SCFI index every Friday at 15:00hrs Beijing Time. Also, as one reviewer mentioned, the freight revenue from a portfolio of operated vessels does not need to be related only to a specific day of the week (Friday), as physical charters could last several weeks. However, the "optimal" hedge rebalancing frequency is left for future research, and as such a weekly frequency is selected which is in accordance with both the general finance and freight derivatives literature.

${ }^{16}$ At the time of writing, dry bulk derivatives prices are provided to the Baltic Exchange by: BRS Brokers, Clarkson Securities Ltd., Freight Investor Services Ltd., BRS Brokers, Clarkson Securities Ltd., Freight Investor Services Ltd., GFI Brokers, Pasternak Baum \& Company Inc., and Simpson Spence \& Young Ltd, Pasternak Baum \& Company Inc., and Simpson Spence \& Young Ltd. Similarly, tanker derivatives prices are reported to the Baltic Exchange by: ACM-GFI joint venture group, Marex Spectron and Howe Robinson Partners.

${ }^{17}$ Thursday prices are considered as the SSE also reports their container index on Thursday when there is a holiday on Friday.

${ }^{18}$ Near-month contracts refer to the monthly-averaged futures contracts, which start from the beginning of next month and mature at the end of next month. Second near-month contracts start in the second following month and settle at the end of second next month. A perpetual contract rollover technique is used at the last trading day of the month, to avoid any price jumps at the expiration period of the derivatives contracts.

${ }^{19} \mathrm{We}$ assume a total transaction cost of $1.5 \%$ for each futures trade, which includes $1 \%$ administrative and brokerage fees (as also assumed by Alizadeh and Nomikos, 2009) plus $0.5 \%$ clearing fees.
} 
their corresponding freight futures contracts. Time charter (T/C) futures are more liquid for Capesize, Panamax and Supramax markets where are TD2 and TC3 route futures and Shanghai-North West Europe and Shanghai-US West coast futures are more liquid for tanker and container segment, respectively. As dry bulk T/C rates are global averages of several freight rate routes, while tanker and container rates represent a single freight route, we employ a control process to verify that there is no discrepancy between holding mixed portfolios of the above freight rates. Therefore, we conduct correlation tests between dry bulk T/C rates and major dry bulk single routes, with results indicating high correlations in all cases. This implies that the T/C rates can be safely used instead of route specific freight rates for the dry bulk segment.

Table 1 reports the descriptive statistics and stationarity test results of logarithmic freight rates and corresponding near-month and second near-month freight futures contracts for the container, dry bulk and tanker sub-sectors. The physical freight rates and freight futures returns are presented in Panels $\mathrm{A}$ and $\mathrm{B}$, respectively. The results indicate that unconditional volatilities of both freight rate and freight futures returns for the NWE route are higher than those for the USWC route. Similarly, the Capesize is the most volatile dry bulk sub-sector, followed by the Panamax and Supramax sub-sectors. In the tanker segment, the TD3 route is more volatile than the TC2 route. Near-month freight futures contracts are more volatile than second near-month futures contracts, which may be due to the surge in last moment trading activities as contracts approach maturity. The stationarity for each returns are determined by the ADF (Dickey and Fuller, 1981) and PP (Phillips and Perron, 1988) unit root tests. Results suggest that all log-prices are non-stationary in levels and stationary in first-differences indicating that the variables are integrated of order one, $I(1)$. After applying the Johansen (1988) cointegration test, results indicate that for all non-stationary price pairs tested, a cointegrating vector exists with a linear combination of freight rates and corresponding freight futures prices. $^{20}$

Table 2 presents the (i) correlations coefficients between the physical freight rates (Panel A), (ii) correlations between freight rates and near-month futures contracts (Panel B), and (iii) correlations between freight rates and second near-month freight futures prices (Panel C). High correlations are observed between the freight rates of each sub-sector; that is, the North-East Europe (NWE) and US West-Coast (USWC) container routes are $41.7 \%$ correlated while

\footnotetext{
${ }^{20}$ Cointegration results are not presented here to conserve space, but they are available upon request.
} 
correlation between Capesize (CAPE), Panamax (PANA) and Supramax (SUPRA) freight rates lie between $25 \%$ to $52 \%$. Correlations between TC2 and TD3 tanker freight rates conversely are very low, which could be the result of the lead-lag relationships between the demand of crude oil and product tankers. The correlations between the three sub-sectors are very low or negative, highlighting the potential diversification benefits from holding a mixed portfolio of sectoral freight rates. Panel $\mathrm{B}$ and $\mathrm{C}$ indicate that, there exists high correlation between freight rates and their corresponding freight futures contracts, in addition to significant cross correlations between freight rates and freight futures contracts within the sub-sector. The cross correlation within container and dry bulk sectors are as high as $18 \%$ and $38 \%$ respectively, whereas cross correlation within tanker sector is relatively low with the highest cross correlation of only $10 \%$. This preliminary analysis provides us an intuition that cross hedge using freight futures contracts can be used to hedge freight rate fluctuations along with direct hedge to improve hedging effectiveness. 
Table 1. Descriptive Statistics of Weekly Logarithms for Freight Rate and Freight Futures

\begin{tabular}{|c|c|c|c|c|c|c|c|c|c|c|c|c|c|c|}
\hline & $T$ & Mean & Std. Dev. & Skew & Kurt & $Q(4)$ & $Q(12)$ & $Q^{2}(4)$ & $Q^{2}(12)$ & ARCH (4) & ARCH (12) & J-B & ADF (lev) & PP (lev) \\
\hline \multicolumn{15}{|c|}{ Panel A: Freight Rate Returns } \\
\hline NWE_S & 202 & -0.00545 & 0.156 & 2.891 & 17.639 & 9.254 & 28.752 & 1.828 & 27.199 & 1.710 & 22.740 & 2084.924 & -13.548 & -13.548 \\
\hline USWC_S & 202 & -0.00047 & 0.054 & 1.541 & 7.453 & 12.158 & 26.577 & 1.152 & 9.715 & 1.117 & 9.904 & 246.855 & -13.119 & -13.119 \\
\hline CAPE_S & 202 & -0.00146 & 0.230 & 0.325 & 4.264 & 31.565 & 78.491 & 8.172 & 19.244 & 7.888 & 18.541 & 16.998 & -9.992 & -9.992 \\
\hline PANA_S & 202 & -0.00517 & 0.132 & 2.171 & 14.532 & 15.807 & 24.430 & 0.043 & 0.984 & 0.042 & 0.958 & 1278.001 & -11.748 & -11.748 \\
\hline SUPRA_S & 202 & -0.00399 & 0.060 & -0.170 & 6.684 & 79.241 & 100.477 & 14.673 & 21.110 & 13.874 & 17.179 & 115.209 & -7.391 & -7.391 \\
\hline TC2_S & 202 & -0.00017 & 0.116 & 0.831 & 5.264 & 2.306 & 12.665 & 0.468 & 10.997 & 0.478 & 15.230 & 66.380 & -15.040 & -15.040 \\
\hline TD3_S & 202 & 0.00130 & 0.109 & 0.122 & 5.840 & 14.086 & 26.826 & 32.906 & 33.893 & 27.306 & 29.165 & 68.404 & -15.429 & -15.429 \\
\hline \multicolumn{15}{|c|}{ Panel B: Freight Futures Returns } \\
\hline NWE_F $F_{1}$ & 202 & -0.00254 & 0.076 & 0.317 & 9.427 & 5.721 & 14.540 & 5.084 & 12.352 & 5.151 & 11.176 & 351.033 & -12.359 & -12.359 \\
\hline NWE_F $F_{2}$ & 202 & -0.00156 & 0.060 & 1.121 & 15.259 & 9.515 & 18.439 & 4.212 & 6.044 & 4.267 & 6.800 & 1307.236 & -12.526 & -12.526 \\
\hline USWC_F $F_{1}$ & 202 & -0.00047 & 0.039 & 0.897 & 10.130 & 1.233 & 20.192 & 1.198 & 8.427 & 1.161 & 8.734 & 454.938 & -13.878 & -13.878 \\
\hline USWC_F $F_{2}$ & 202 & -0.00022 & 0.038 & -0.837 & 12.457 & 5.600 & 14.592 & 8.293 & 13.800 & 16.511 & 20.643 & 776.337 & -16.250 & -16.250 \\
\hline $\mathrm{CAPE}_{-} F_{1}$ & 202 & -0.00316 & 0.175 & -0.064 & 3.278 & 9.108 & 24.035 & 0.570 & 8.502 & 0.789 & 9.371 & 0.789 & -14.499 & -14.499 \\
\hline $\mathrm{CAPE}_{-} F_{2}$ & 202 & -0.00423 & 0.135 & -0.429 & 4.823 & 6.410 & 16.226 & 0.419 & 2.730 & 0.426 & 2.453 & 34.170 & -14.884 & -14.884 \\
\hline PANA_F $F_{1}$ & 202 & -0.00527 & 0.107 & 0.651 & 6.482 & 2.724 & 6.840 & 2.706 & 3.624 & 2.333 & 2.956 & 116.319 & -14.903 & -14.903 \\
\hline PANA_F $F_{2}$ & 202 & -0.00561 & 0.078 & 0.744 & 5.477 & 1.733 & 9.524 & 11.903 & 20.837 & 11.248 & 20.468 & 70.271 & -13.604 & -13.604 \\
\hline SUPRA_F $F_{1}$ & 202 & -0.00390 & 0.071 & 0.083 & 3.550 & 6.554 & 14.442 & 4.230 & 8.103 & 3.438 & 7.227 & 2.781 & -14.245 & -14.245 \\
\hline SUPRA_F $F_{2}$ & 202 & -0.00408 & 0.061 & -0.687 & 5.614 & 6.347 & 11.686 & 8.366 & 12.793 & 8.744 & 12.763 & 73.406 & -13.192 & -13.192 \\
\hline TC2_F $F_{1}$ & 202 & -0.00002 & 0.074 & 0.048 & 4.000 & 10.739 & 22.933 & 6.202 & 11.263 & 5.095 & 10.457 & 8.504 & -17.394 & -17.394 \\
\hline $\mathrm{TC} 2 F_{2}$ & 202 & -0.00038 & 0.053 & -0.304 & 5.195 & 17.419 & 39.904 & 24.874 & 25.954 & 26.529 & 28.003 & 43.675 & -19.390 & -19.390 \\
\hline TD3_F $F_{1}$ & 202 & 0.00030 & 0.080 & 0.630 & 6.358 & 12.020 & 15.862 & 19.435 & 23.248 & 16.235 & 19.611 & 108.243 & -16.067 & -16.067 \\
\hline TD3_F $F_{2}$ & 202 & -0.00010 & 0.055 & 0.973 & 6.994 & 8.134 & 10.508 & 5.517 & 8.734 & 5.097 & 8.116 & 166.134 & -15.336 & -15.336 \\
\hline
\end{tabular}

Notes: $S$ and $F_{1}\left(F_{2}\right)$ represent corresponding freight rates and near-month (second near-month) freight futures returns, respectively. For example, NWE_S and USWC_ $F_{2}$ represent NWE (North deviation of the series, respectively. Skew and Kurt) second near-month futures returns, respectively. $T$ is the number of observations. Mean and Std. Dev. are the sample mean and 2 and test for normality. $Q(4)$ and $Q^{2}(4)$ are the Ljung and Box (1978) $Q$-statistic on the first 4 lags of the sample autocorrelation function of the raw price series and the squared price series, respectively; the statistic is distributed as $\chi^{2}(4)$. ARCH(4) is the Engle (1982) test for ARCH effects; the statistic is distributed as $\chi^{2}(4)$; Similar tests are also conducted for 12 lags with qualitatively the same results. 
Table 2. Correlations between Weekly Logarithm of Freight Rates and Freight Futures

\begin{tabular}{|c|c|c|c|c|c|c|c|}
\hline \multicolumn{8}{|c|}{ Panel A: Freight Rates } \\
\hline & $\overline{\text { NWE_S }}$ & USWC_S & CAPE_S & PANA_S & SUPRA_S & TC2_S & TD3_S \\
\hline NWE_S & 1 & & & & & & \\
\hline USWC_ $S$ & 0.417 & 1 & & & & & \\
\hline CAPE_ $S$ & 0.025 & -0.101 & 1 & & & & \\
\hline PANA_ $S$ & -0.102 & -0.105 & 0.329 & 1 & & & \\
\hline SUPRA_S & -0.057 & -0.138 & 0.250 & 0.519 & 1 & & \\
\hline TC2 $s$ & 0.053 & 0.032 & 0.016 & -0.066 & -0.022 & 1 & \\
\hline TD3_ $S$ & -0.087 & -0.117 & 0.104 & 0.136 & 0.071 & -0.011 & 1 \\
\hline \multicolumn{8}{|c|}{ Panel B: Freight Rates and Near-month Futures } \\
\hline & NWE $S$ & USWC $S$ & CAPE $S$ & PANA $S$ & SUPRA $S$ & TC2 $S$ & TD3 $s$ \\
\hline $\mathrm{NWE}_{-} F_{1}$ & 0.314 & 0.179 & -0.066 & -0.071 & -0.027 & -0.028 & -0.149 \\
\hline USWC_F 1 & 0.081 & 0.382 & -0.115 & -0.011 & -0.080 & 0.032 & -0.094 \\
\hline CAPE $F_{1}$ & 0.091 & 0.015 & 0.641 & 0.198 & 0.098 & -0.010 & 0.084 \\
\hline PANA_F $F_{1}$ & -0.080 & -0.071 & 0.298 & 0.548 & 0.181 & -0.049 & 0.076 \\
\hline SUPRA $F_{1}$ & -0.121 & -0.119 & 0.237 & 0.433 & 0.476 & -0.028 & 0.050 \\
\hline TC2_F $F_{1}^{-}$ & 0.076 & 0.031 & -0.036 & -0.035 & -0.050 & 0.520 & 0.099 \\
\hline TD3_F 1 & 0.035 & -0.035 & 0.056 & 0.136 & 0.045 & -0.082 & 0.641 \\
\hline \multicolumn{8}{|c|}{ Panel C: Freight Rates and Second near-month Futures } \\
\hline & NWE_S & USWC_S & CAPE_S & PANA_S & SUPRA_S & TC2_S & TD3_S \\
\hline NWE $F_{2}$ & 0.223 & 0.122 & -0.010 & -0.134 & -0.142 & -0.005 & -0.075 \\
\hline USWC $_{-} F_{2}$ & 0.073 & 0.244 & -0.118 & -0.082 & -0.120 & 0.081 & -0.095 \\
\hline $\mathrm{CAPE}_{-} F_{2}$ & -0.011 & 0.011 & 0.493 & 0.106 & 0.066 & -0.014 & -0.011 \\
\hline PANA $F_{2}$ & -0.081 & -0.050 & 0.291 & 0.464 & 0.133 & -0.066 & 0.027 \\
\hline SUPRA__ $F_{2}$ & -0.198 & -0.066 & 0.235 & 0.377 & 0.355 & -0.027 & -0.037 \\
\hline TC2 $F_{2}$ & -0.013 & -0.045 & -0.012 & -0.009 & -0.036 & 0.284 & 0.094 \\
\hline TD3_F $F_{2}$ & -0.049 & -0.059 & 0.130 & 0.204 & 0.039 & -0.084 & 0.524 \\
\hline
\end{tabular}

Notes: See notes of Table 1 for the definitions of the variables.

\section{Empirical Results}

Both in-sample and out-of-sample tests are performed to investigate the performance of the well-diversified portfolio comprising physical freight rates, as well as, the direct hedge and cross hedge portfolios comprising also freight futures. In-sample tests are performed from February 2011 to April 2015 based on a total of 202 observations (weekly), while weekly rolling out-of-sample tests are conducted from April 2015 to June 2016 based on 60 observations.

\subsection{Performance of Well-Diversified Portfolio of Freight Rates}

Due to the negative correlations between container, dry bulk and tanker freight rates, as seen in Table 2, we investigate if shipping market practitioners can minimise their freight rate 
exposure through holding a well-diversified portfolio of freight routes. ${ }^{21}$ The VR and UI of the well-diversified portfolio, over and above an equally weighted portfolio of freight rates, are presented in Table 3. ${ }^{22}$ In-sample and out-of-sample tests are reported in Panels A and B, respectively. Results indicate that, there is a significant decrease in the variance of the welldiversified portfolio relative to an equally weighted portfolio in all scenarios examined. Insample and out-of-sample tests suggest that, the well-diversified portfolio reduces freight rate risks between $28-48 \%$ and $32-48 \%$, respectively with an exception of scenario $6 .{ }^{23}$ The welldiversified portfolio for the base scenario, comprising of freight rates in all three sub-sectors, produces a $V R$ out-of-sample of up to $42 \%$. Moreover, we document a utility increase in all scenarios (except again in scenario 6 for out-of-sample observation) for the well-diversified portfolio. Overall, the findings suggest that the traditional freight rate risk management through portfolio diversification can be an effective risk management solution.

Table 3. Performance of Well-Diversified Portfolio of Freight Rates

\begin{tabular}{|c|c|c|c|c|c|c|c|}
\hline & $\begin{array}{l}\text { Base } \\
\text { Scenario }\end{array}$ & Scenario 1 & Scenario 2 & Scenario 3 & Scenario 4 & Scenario 5 & Scenario 6 \\
\hline \multicolumn{8}{|c|}{ Panel A: In-Sample Performance } \\
\hline$\sigma_{E W}^{2}$ & 0.05612 & 0.07070 & 0.07434 & 0.06002 & 0.09011 & 0.11049 & 0.07767 \\
\hline$\sigma_{W D}^{2}$ & 0.03320 & 0.03699 & 0.04821 & 0.04324 & 0.05425 & 0.05974 & 0.07754 \\
\hline$V R_{W D \_E W}$ & $40.84 \%$ & $47.68 \%$ & $35.16 \%$ & $27.96 \%$ & $39.80 \%$ & $45.93 \%$ & $0.17 \%$ \\
\hline$U_{E W}$ & -0.00535 & -0.00831 & -0.00742 & -0.00480 & -0.01108 & -0.01575 & -0.00547 \\
\hline$U_{W D}$ & -0.00267 & -0.00349 & -0.00469 & -0.00197 & -0.00349 & -0.00756 & -0.00540 \\
\hline$U I_{W D \_E W}$ & 0.00268 & 0.00482 & 0.00274 & 0.00282 & 0.00759 & 0.00819 & 0.00006 \\
\hline \multicolumn{8}{|c|}{ Panel B: Out-of-Sample Performance } \\
\hline$\sigma_{E W}^{2}$ & 0.06194 & 0.07911 & 0.07658 & 0.07279 & 0.12401 & 0.11110 & 0.08191 \\
\hline$\sigma_{W D}^{2}$ & 0.03626 & 0.04147 & 0.04874 & 0.04928 & 0.06802 & 0.05950 & 0.08168 \\
\hline$V R_{W D_{-} E W}$ & $41.49 \%$ & $47.61 \%$ & $36.35 \%$ & $32.25 \%$ & $45.03 \%$ & $46.45 \%$ & $0.27 \%$ \\
\hline$U_{E W}$ & -0.00598 & -0.00923 & -0.00762 & -0.00693 & -0.01878 & -0.01520 & -0.00682 \\
\hline$U_{W D}$ & -0.00365 & -0.00468 & -0.00499 & -0.00365 & -0.00669 & -0.00737 & -0.00685 \\
\hline$U I_{W D \_E W}$ & 0.00233 & 0.00455 & 0.00263 & 0.00328 & 0.01209 & 0.00783 & -0.00004 \\
\hline
\end{tabular}

Notes: $\sigma_{E W}^{2}\left(\sigma_{W D}^{2}\right)$ and $U_{E W}\left(U_{W D}\right)$ denote variances and utilities of an equally weighted (well-diversified) portfolio of freight rates, respectively. $U_{E W}$ and $U_{W D}$ are calculated for coefficient of risk aversion (k) equal to $1 . V R_{W D_{-} E W}$ and $U I_{W D_{E} E W}$ are the variance reduction $(V R)$ and utility increase $(U I)$ of the well-diversified portfolio with respect to an equally weighted portfolio of freight rates.

\footnotetext{
${ }^{21}$ The efficient risk-return portfolio, is divided into 100 parts, generating 100 portfolios of different freight rate weights. Therefore, the weights of the portfolio of freight rates on the efficient risk-return frontier for various scenarios are not presented in the text but are available to readers upon request.

${ }^{22}$ An equally weight portfolio of freight rate is used as a benchmark.

${ }^{23}$ Scenario 6, TC2 and TD3 freight rate routes produce very low correlation as presented in Table 2. This results in not effective reduction of variance through diversification.
} 


\subsection{Performance of Direct Hedge Portfolio}

Results for in-sample and out-of-sample $V R$ (and $U I$ ) for both near-month and second nearmonth freight futures contracts are presented in Tables $4 \mathrm{a}$ and $4 \mathrm{~b}$, respectively. In the container USWC route, time varying and naïve hedge ratio seems to produce highest $V R$ of $10.88 \%$ (4.48\%) and $21.33 \%(12.50 \%)$ for in-sample and out-of-sample near-month (second nearmonth) freight futures, respectively. The opposite is found for the container NWE route, with the time-varying VECM-GARCH model outperforming all other specifications, with a $V R$ of $10.30 \%(10.16 \%)$ and $10.10 \%(3.02 \%)$ for in-sample and out-of-sample near-month (second near-month) freight futures, respectively. ${ }^{24}$ Overall, near-month freight futures perform better than second near-month freight futures for the container sub-sector. This may be attributed to an increase in last minute trading activity on the back of more market information typically incorporated in near-month futures contracts approaching maturity compared to second nearmonth contracts. Further, the USWC freight futures performs better than the NWE freight futures (for out-of-sample analysis), reflected in the higher freight rate variance of the latter route. This may be driven by the lower number of liner services in the Shanghai-US route pointing to a more stable freight rate environment in this case. ${ }^{25}$

In-sample tests for the dry bulk sub-sector suggest that the conventional OLS model generates the highest hedging effectiveness for Capesize and Panamax freight futures, with a $V R$ of $38.13 \%$ $(22.76 \%)$ and $31.20 \%(23.48 \%)$ for near-month (second near-month) freight futures, respectively. In contrast, for Supramax freight futures, the VECM-GARCH model exhibits the highest $V R$ of $19.25 \%$ (14.62\%) for near-month (second near-month) freight futures contracts. Out-of-sample tests suggest that the VECM-GARCH (VECM) model produces the highest VR of $33.48 \%(13.38 \%)$ for near-month (second near-month) Supramax freight futures. Further a naïve hedge ratio model performs better for Capesize freight rates with $V R$ of $47.51 \%(27.44 \%)$ for near month (second near-month) freight futures contracts. Panamax freight futures generate highest hedging effectiveness using OLS (VECM-GARCH) model for near-month (second near-month) contracts with VR of $21.91 \%$ (10.26\%). Overall, the Capesize freight futures have the highest performance due to their higher liquidity in terms of trading volume. It appears that

\footnotetext{
${ }^{24}$ Except of second near-month NWE futures contracts is observed, where conventional OLS model generates highest $V R$ of $10.77 \%$

${ }^{25}$ During the sample period (2011-2016), Europe imported on average 34 million TEU containers annually, whereas US imported on average only 21 million TEU containers annually.
} 
similar to container futures, near-month dry bulk freight futures perform better than second near-month freight futures.

Time varying hedge ratio using VECM GARCH model generates highest hedging effectiveness for in-sample analysis with tanker freight futures contracts with $V R$ of $27.52 \%$ (10.04\%) and 48.22\% (32.47\%) for near-month (second near-month) TC2 and TD3 futures contracts respectively. In contract, constant hedge ratios perform better for out-of-sample analysis with $V R$ of as high as $29.17 \%$ (19.03\%) and 34.31\% (23.45\%) for near-month (second near-month) TC2 and TD3 futures contracts respectively. TD3 freight futures contracts perform better than TC2 freight futures contracts.

In general, results suggest that the $V R$ for all models and across all different freight futures is relatively low, with an average of around $20 \%$. In addition, all freight futures prices seem to follow a martingale process, with the MVHR to be equal to the UMHR for all coefficients of risk aversion. This limit the usefulness of freight futures contracts for investment/speculative purposes, which could be attributed to the low market liquidity, creating sticky (stale) prices. Thus, the $U I$ criterion is estimated only for the case of the risk neutral $(k=1)$ participant as a measure of the increase of the utility function due to hedging. In-sample tests indicate that both the OLS and VECM-GARCH models perform similarly, whereas out-of-sample tests indicate that the OLS model performs best in most scenarios.

Finally, we investigate if the risks associated with the well-diversifying portfolio of physical freight rates are further reduced when using freight futures. To this end, freight futures contracts are added to the well-diversified portfolio, where the weights of these futures contracts are estimated using the MVHR of Equation (3) (see Portfolio 2, Constraint C, in Section 2.2). The decision to keep the weights of the physical freight rates unchanged, while hedging the freight rate exposure, is motivated by the fact that practitioners tend to open positions in the physical freight market by considering the risk-return trade-off of this market, rather than that of the freight derivatives market. 
Table 4a. Direct Hedge Performance: In-Sample Tests

\begin{tabular}{|c|c|c|c|c|c|c|c|c|c|c|c|c|c|c|}
\hline & \multicolumn{7}{|c|}{ Near-Month Contracts } & \multicolumn{7}{|c|}{ Second Near-Month Contracts } \\
\hline & \multicolumn{2}{|c|}{ Container } & \multicolumn{3}{|c|}{ Dry Bulk } & \multicolumn{2}{|c|}{ Tanker } & \multicolumn{2}{|c|}{ Container } & \multicolumn{3}{|c|}{ Dry Bulk } & \multicolumn{2}{|c|}{ Tanker } \\
\hline & NWE_1 & USWC_1 & CAPE_1 & PANA_1 & SUPRA_1 & TC2_1 & TD3_1 & NWE_2 & USWC_2 & CAPE_2 & PANA_2 & SUPRA_2 & TC2_2 & TD3_2 \\
\hline \multicolumn{15}{|c|}{ Panel 1a: Minimum Variance Hedge Ratio - MVHR } \\
\hline Naïve & 1 & 1 & 1 & 1 & 1 & 1 & 1 & 1 & 1 & 1 & 1 & 1 & 1 & 1 \\
\hline OLS & 0.54 & 0.45 & 0.81 & 0.69 & 0.36 & 0.80 & 0.95 & 0.85 & 0.29 & 0.82 & 0.82 & 0.34 & 0.53 & 1.10 \\
\hline VECM & 0.51 & 0.45 & 0.81 & 0.73 & 0.39 & 0.87 & 0.95 & 0.85 & 0.27 & 0.87 & 0.91 & 0.38 & 0.74 & 1.08 \\
\hline VECM-GARCH & - & - & - & - & - & - & - & - & - & - & - & - & - & - \\
\hline \multicolumn{15}{|c|}{ Panel 1b: Variance of Hedged Portfolio } \\
\hline Unhedged & 0.02432 & 0.00295 & 0.05313 & 0.01733 & 0.00357 & 0.01345 & 0.01195 & 0.02432 & 0.00295 & 0.05313 & 0.01733 & 0.00357 & 0.01345 & 0.01195 \\
\hline Naïve & 0.02379 & 0.00311 & 0.03384 & 0.01304 & 0.00493 & 0.00996 & 0.00626 & 0.02179 & 0.00357 & 0.04168 & 0.01346 & 0.00475 & 0.01276 & 0.00831 \\
\hline OLS & 0.02260 & 0.00264 & 0.03287 & 0.01192 & 0.00289 & 0.00975 & 0.00624 & 0.02170 & 0.00282 & 0.04104 & 0.01326 & 0.00313 & 0.01234 & 0.00828 \\
\hline VECM & 0.02261 & 0.00264 & 0.03287 & 0.01194 & 0.00289 & 0.00977 & 0.00624 & 0.02170 & 0.00282 & 0.04110 & 0.01331 & 0.00313 & 0.01238 & 0.00829 \\
\hline VECM-GARCH & 0.02182 & 0.00263 & 0.03291 & 0.01196 & 0.00288 & 0.00975 & 0.00619 & 0.02185 & 0.00282 & 0.03972 & 0.01326 & 0.00305 & 0.01210 & 0.00807 \\
\hline \multicolumn{15}{|c|}{ Panel 1c: Variance Reduction - VR } \\
\hline Naïve & $2.19 \%$ & $-5.48 \%$ & $36.31 \%$ & $24.76 \%$ & $-38.17 \%$ & $25.97 \%$ & $47.62 \%$ & $10.42 \%$ & $-20.98 \%$ & $21.56 \%$ & $22.34 \%$ & $-32.99 \%$ & $5.08 \%$ & $30.45 \%$ \\
\hline OLS & $7.09 \%$ & $10.43 \%$ & $38.13 \% *$ & $31.20 \% *$ & $19.00 \%$ & $27.54 \%$ & $47.76 \%$ & $10.77 \% *$ & $4.20 \%$ & $22.76 \%$ & $23.48 \% *$ & $12.39 \%$ & $8.21 \%$ & $30.68 \%$ \\
\hline VECM & $7.06 \%$ & $10.43 \%$ & $38.13 \%$ & $31.08 \%$ & $18.92 \%$ & $27.34 \%$ & $47.76 \%$ & $10.77 \%$ & $4.17 \%$ & $22.63 \%$ & $23.18 \%$ & $12.20 \%$ & $7.92 \%$ & $30.67 \%$ \\
\hline VECM-GARCH & $10.30 \% *$ & $10.88 \% *$ & $38.05 \%$ & $31.02 \%$ & $19.25 \% *$ & $27.52 \% *$ & $48.22 \% *$ & $10.16 \%$ & $4.48 \% *$ & $25.24 \% *$ & $23.47 \%$ & $14.62 \% *$ & $10.04 \% *$ & $32.47 \% *$ \\
\hline \multicolumn{15}{|c|}{ Panel 2a: Expected Utility $(k=1)$} \\
\hline Unhedged & -0.02953 & -0.00328 & -0.05539 & -0.02290 & -0.00782 & -0.01432 & -0.01107 & -0.02953 & -0.00328 & -0.05539 & -0.02290 & -0.00782 & -0.01432 & -0.01107 \\
\hline Naïve & -0.02633 & -0.00298 & -0.03101 & -0.01289 & -0.00478 & -0.01096 & -0.00512 & -0.02533 & -0.00368 & -0.03909 & -0.01313 & -0.00469 & -0.01412 & -0.00709 \\
\hline OLS & -0.02636 & -0.00277 & -0.03106 & -0.01357 & -0.00555 & -0.01075 & -0.00512 & -0.02550 & -0.00310 & -0.03939 & -0.01400 & -0.00592 & -0.01354 & -0.00703 \\
\hline VAR & -0.02646 & -0.00277 & -0.03103 & -0.01336 & -0.00546 & -0.01078 & -0.00512 & -0.02549 & -0.00310 & -0.03917 & -0.01352 & -0.00576 & -0.01365 & -0.00704 \\
\hline VAR-GARCH & -0.02383 & -0.00285 & -0.03134 & -0.01316 & -0.00548 & -0.01047 & -0.00480 & -0.02400 & -0.00334 & -0.03984 & -0.01386 & -0.00515 & -0.01194 & -0.00754 \\
\hline \multicolumn{15}{|c|}{ Panel 2b: Utility Increase - $U I(k=1)$} \\
\hline Naïve & 0.00320 & 0.00030 & $0.02437 *$ & $0.01001 *$ & $0.00304 *$ & 0.00336 & 0.00594 & 0.00420 & -0.00040 & $0.01629 *$ & $0.00977 *$ & $0.00313^{*}$ & 0.00021 & 0.00397 \\
\hline OLS & 0.00317 & 0.00051 & 0.02433 & 0.00933 & 0.00227 & 0.00357 & 0.00594 & 0.00403 & $0.00018^{*}$ & 0.01600 & 0.00890 & 0.00190 & 0.00078 & $0.00404 *$ \\
\hline VAR & 0.00307 & $0.00052 *$ & 0.02436 & 0.00955 & 0.00236 & 0.00355 & 0.00594 & 0.00404 & 0.00018 & 0.01622 & 0.00939 & 0.00206 & 0.00068 & 0.00403 \\
\hline VAR-GARCH & $0.00570^{*}$ & 0.00043 & 0.02405 & 0.00974 & 0.00234 & $0.00385^{*}$ & $0.00626^{*}$ & $0.00553^{*}$ & -0.00006 & 0.01555 & 0.00904 & 0.00267 & $0.00238^{*}$ & 0.00353 \\
\hline
\end{tabular}


Table 4b. Direct Hedge Performance: Out-of-Sample Tests

\begin{tabular}{|c|c|c|c|c|c|c|c|c|c|c|c|c|c|c|}
\hline & \multicolumn{7}{|c|}{ Near-Month Contracts } & \multicolumn{7}{|c|}{ Second Near-Month Contracts } \\
\hline & \multicolumn{2}{|c|}{ Container } & \multicolumn{3}{|c|}{ Dry Bulk } & \multicolumn{2}{|c|}{ Tanker } & \multicolumn{2}{|c|}{ Container } & \multicolumn{3}{|c|}{ Dry Bulk } & \multicolumn{2}{|c|}{ Tanker } \\
\hline & NWE_1 & USWC_1 & CAPE_1 & PANA_1 & SUPRA_1 & TC2_1 & TD3_1 & NWE_2 & USWC_2 & CAPE_2 & PANA_2 & SUPRA_2 & TC2_2 & TD3_2 \\
\hline \multicolumn{15}{|c|}{ Panel 1a: Variance of Hedged Portfolio } \\
\hline Unhedged & 0.18372 & 0.01811 & 0.09001 & 0.00852 & 0.00429 & 0.00935 & 0.04127 & 0.18372 & 0.01811 & 0.09001 & 0.00852 & 0.00429 & 0.00935 & 0.04127 \\
\hline Naïve & 0.15919 & 0.01425 & 0.04725 & 0.00975 & 0.00378 & 0.00701 & 0.02711 & 0.17899 & 0.01585 & 0.06531 & 0.00955 & 0.00522 & 0.00772 & 0.03184 \\
\hline OLS & 0.16568 & 0.01548 & 0.04773 & 0.00666 & 0.00289 & 0.00663 & 0.02730 & 0.17962 & 0.01704 & 0.06600 & 0.00786 & 0.00372 & 0.00769 & 0.03159 \\
\hline VECM & 0.16562 & 0.01525 & 0.04741 & 0.00681 & 0.00290 & 0.00671 & 0.02725 & 0.17976 & 0.01701 & 0.06563 & 0.00827 & 0.00372 & 0.00757 & 0.03160 \\
\hline VECM-GARCH & 0.16517 & 0.01557 & 0.04769 & 0.00693 & 0.00286 & 0.00678 & 0.02935 & 0.17816 & 0.01674 & 0.06671 & 0.00765 & 0.00377 & 0.00778 & 0.03216 \\
\hline \multicolumn{15}{|c|}{ Panel 1b: Variance Reduction - VR } \\
\hline Naïve & $13.35 \%$ & $21.33 \% *$ & $47.51 \% *$ & $-14.43 \%$ & $12.00 \%$ & $25.10 \%$ & $34.31 \% *$ & $2.58 \%$ & $12.50 \% *$ & $27.44 \% *$ & $-12.04 \%$ & $-21.48 \%$ & $17.50 \%$ & $22.84 \%$ \\
\hline OLS & $9.82 \%$ & $14.55 \%$ & $46.98 \%$ & $21.91 \% *$ & $32.68 \%$ & $29.17 \% *$ & $33.85 \%$ & $2.23 \%$ & $5.90 \%$ & $26.67 \%$ & $7.83 \%$ & $13.37 \%$ & $17.84 \%$ & $23.45 \% *$ \\
\hline VECM & $9.85 \%$ & $15.81 \%$ & $47.33 \%$ & $20.12 \%$ & $32.56 \%$ & $28.32 \%$ & $33.97 \%$ & $2.16 \%$ & $6.09 \%$ & $27.09 \%$ & $3.00 \%$ & $13.38 \% *$ & $19.03 \% *$ & $23.44 \%$ \\
\hline VECM-GARCH & $10.10 \% *$ & $14.01 \%$ & $47.02 \%$ & $18.70 \%$ & $33.48 \% *$ & $27.56 \%$ & $28.88 \%$ & $3.02 \% *$ & $7.55 \%$ & $25.89 \%$ & $10.26 \% *$ & $12.15 \%$ & $16.86 \%$ & $22.08 \%$ \\
\hline \multicolumn{15}{|c|}{ Panel 2a: Expected Utility $(k=1)$} \\
\hline Unhedged & -0.17483 & -0.03091 & -0.08335 & -0.01001 & -0.00528 & -0.01744 & -0.05204 & -0.17483 & -0.03091 & -0.08335 & -0.01001 & -0.00528 & -0.01744 & -0.05204 \\
\hline Naïve & -0.14284 & -0.01573 & -0.04443 & -0.00908 & -0.00361 & -0.00825 & -0.02999 & -0.16000 & -0.01696 & -0.06221 & -0.01051 & -0.00498 & -0.01073 & -0.03504 \\
\hline OLS & -0.15213 & -0.02249 & -0.04369 & -0.00653 & -0.00390 & -0.00923 & -0.02985 & -0.16179 & -0.02608 & -0.06252 & -0.00897 & -0.00444 & -0.01241 & -0.03339 \\
\hline VECM & -0.15190 & -0.02190 & -0.04347 & -0.00660 & -0.00363 & -0.00888 & -0.02983 & -0.16156 & -0.02614 & -0.06247 & -0.00938 & -0.00435 & -0.01178 & -0.03342 \\
\hline VAR-GARCH & -0.15087 & -0.02109 & -0.04386 & -0.00533 & -0.00426 & -0.00906 & -0.03175 & -0.14977 & -0.02228 & -0.06449 & -0.00908 & -0.00407 & -0.01096 & -0.03513 \\
\hline \multicolumn{15}{|c|}{ Panel 2b: Utility Increase - UI $(k=1)$} \\
\hline Naïve & $0.03199 *$ & $0.01518^{*}$ & 0.03891 & 0.00092 & $0.00166^{*}$ & $0.00919 *$ & 0.02205 & 0.01483 & $0.01395^{*}$ & $0.02114 *$ & -0.00050 & 0.00029 & $0.00671^{*}$ & 0.01699 \\
\hline OLS & 0.02270 & 0.00842 & 0.03966 & 0.00347 & 0.00137 & 0.00821 & 0.02219 & 0.01305 & 0.00483 & 0.02083 & $0.00104 *$ & 0.00083 & 0.00503 & $0.01865 *$ \\
\hline VECM & 0.02294 & 0.00901 & $0.03987 *$ & 0.00341 & 0.00164 & 0.00856 & $0.02220 *$ & 0.01327 & 0.00477 & 0.02088 & 0.00062 & 0.00093 & 0.00566 & 0.01862 \\
\hline VECM-GARCH & 0.02397 & 0.00982 & 0.03949 & $0.00467 *$ & 0.00102 & 0.00838 & 0.02029 & $0.02507 *$ & 0.00863 & 0.01886 & 0.00092 & $0.00121 *$ & 0.00648 & 0.01691 \\
\hline
\end{tabular}

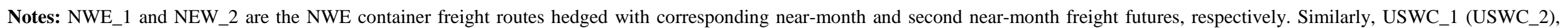

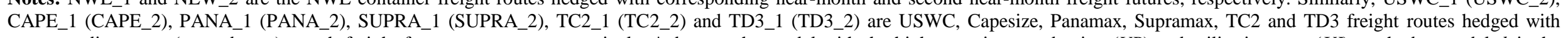
corresponding near- (second near) month freight futures contracts, respectively. ${ }^{*}$ denotes the model with the highest variance reduction $(V R)$ and utility increase $(U I)$ per hedge model. $k$ is the coefficient of risk aversion. 
Table 5 presents the $V R$ and $U I$ of the direct hedge portfolio over and above the well-diversified portfolio of freight rates, for both in-sample and out-of-sample tests, Equations (19) and (20). Results indicate that the direct hedge portfolio using freight futures further decrease the freight rate risk associated with the well-diversified portfolio of freight rates up to as high as $17.52 \%$ (observed in out-of-sample analysis for scenario 6). We also observe that the $U I$ for all the scenarios are positive indicating that usage of freight futures contracts with a direct hedge approach increases the satisfaction level of the hedgers in addition to the traditional optimal diversification. Further, near-month freight futures contracts produce higher $V R$ as compared to second near-month futures contracts. Overall, the models in-sample and out-of-sample perform similarly, with the highest $V R$ observed in Scenario 6. This indicates that market participants with a mixed portfolio of tanker freight rate routes will receive the highest risk minimization through freight futures hedging.

Table 5. Direct Hedge vs. Well-diversified Portfolio Performance

\begin{tabular}{|c|c|c|c|c|c|c|c|}
\hline & $\begin{array}{l}\text { Base } \\
\text { Scenario }\end{array}$ & Scenario 1 & Scenario 2 & Scenario 3 & Scenario 4 & Scenario 5 & Scenario 6 \\
\hline \multicolumn{8}{|c|}{ Panel A: In-Sample Performance } \\
\hline$\overline{\sigma_{W D}^{2}}$ & 0.03320 & 0.03699 & 0.04821 & 0.04324 & 0.05425 & 0.05974 & 0.07754 \\
\hline$\sigma_{D H, 1}^{2}$ & 0.02978 & 0.03395 & 0.04335 & 0.03793 & 0.05135 & 0.05379 & 0.06497 \\
\hline$V R_{D H_{-} W D, 1}$ & $10.31 \%$ & $8.23 \%$ & $10.08 \%$ & $12.28 \%$ & $5.34 \%$ & $9.97 \%$ & $16.21 \%$ \\
\hline$\sigma_{D H, 2}^{2}$ & 0.03114 & 0.03489 & 0.04581 & 0.04088 & 0.05308 & 0.05600 & 0.07259 \\
\hline$V R_{D H_{-} W D, 2}$ & $6.20 \%$ & $5.70 \%$ & $4.98 \%$ & $5.45 \%$ & $2.14 \%$ & $6.26 \%$ & $6.38 \%$ \\
\hline$U_{W D}$ & -0.00267 & -0.00349 & -0.00469 & -0.00197 & -0.00349 & -0.00756 & -0.00540 \\
\hline$U_{D H, 1}$ & -0.00185 & -0.00247 & -0.00338 & -0.00145 & -0.00295 & -0.00546 & -0.00375 \\
\hline$U I_{D H_{-} W D, 1}$ & 0.00083 & 0.00102 & 0.00131 & 0.00052 & 0.00053 & 0.00210 & 0.00165 \\
\hline$U_{D H, 2}$ & -0.00194 & -0.00261 & -0.00352 & -0.00168 & -0.00328 & -0.00573 & -0.00451 \\
\hline$U I_{D H_{-} W D, 2}$ & 0.00073 & 0.00088 & 0.00117 & 0.00029 & 0.00021 & 0.00182 & 0.00090 \\
\hline \multicolumn{8}{|c|}{ Panel B: Out-of-Sample Performance } \\
\hline$\overline{\sigma_{W D}^{2}}$ & 0.03626 & 0.04147 & 0.04874 & 0.04928 & 0.06802 & 0.05950 & 0.08168 \\
\hline$\sigma_{D H, 1}^{2}$ & 0.03281 & 0.03813 & 0.04324 & 0.04343 & 0.06390 & 0.05311 & 0.06736 \\
\hline$V R_{D H_{-} W D, 1}$ & $9.50 \%$ & $8.04 \%$ & $11.27 \%$ & $11.73 \%$ & $5.89 \%$ & $10.70 \%$ & $17.52 \%$ \\
\hline$\sigma_{D H, 2}^{2}$ & 0.03468 & 0.03932 & 0.04607 & 0.04719 & 0.06593 & 0.05573 & 0.07541 \\
\hline$V R_{D H_{-} W D, 2}$ & $4.01 \%$ & $4.83 \%$ & $5.42 \%$ & $3.68 \%$ & $2.40 \%$ & $6.29 \%$ & $7.56 \%$ \\
\hline$U_{W D}$ & -0.00365 & -0.00468 & -0.00499 & -0.00365 & -0.00669 & -0.00737 & -0.00685 \\
\hline$U_{D H, 1}$ & -0.00231 & -0.00302 & -0.00346 & -0.00232 & -0.00482 & -0.00514 & -0.00466 \\
\hline$U I_{D H \_W D, 1}$ & 0.00134 & 0.00166 & 0.00153 & 0.00133 & 0.00186 & 0.00223 & 0.00220 \\
\hline$U_{D H, 2}$ & -0.00261 & -0.00335 & -0.00378 & -0.00287 & -0.00554 & -0.00556 & -0.00574 \\
\hline$U I_{D H_{-} W D, 2}$ & 0.00103 & 0.00133 & 0.00121 & 0.00078 & 0.00115 & 0.00181 & 0.00111 \\
\hline
\end{tabular}




\subsection{Performance of Cross Hedge Portfolio}

As a last step, we estimate a cross hedge portfolio of freight futures to hedge the risks associated with the well-diversified portfolio of physical freight rates without changing the weights of the freight rates within the latter portfolio. ${ }^{26}$ Similar to the previous section, $V R$ and $U I$ are used as measures of hedging performance of the cross hedge portfolio over and above the well-diversified portfolio of freight rates. Results presented in Table 6 indicate that, the cross hedge portfolio using freight futures can further reduce the risks associated with the welldiversified portfolio of freight rates. The results are qualitatively similar both in-sample and out-of-sample. ${ }^{27}$ Further, near-month futures contracts generate higher hedging effectiveness than second-month futures contracts. Similar to the direct hedge portfolio, the UI of the cross hedge portfolio over and above the well-diversified portfolio are positive for all the scenarios.

Table 6. Cross Hedge vs. Well-diversified Portfolio Performance

\begin{tabular}{|c|c|c|c|c|c|c|c|}
\hline & $\begin{array}{l}\text { Base } \\
\text { Scenario } \\
\end{array}$ & Scenario 1 & Scenario 2 & Scenario 3 & Scenario 4 & Scenario 5 & Scenario 6 \\
\hline \multicolumn{8}{|c|}{ Panel A: In-Sample Performance } \\
\hline$\overline{\sigma_{W D}^{2}}$ & 0.03320 & 0.03699 & 0.04821 & 0.04324 & 0.05425 & 0.05974 & 0.07754 \\
\hline$\sigma_{C H, 1}^{2}$ & 0.02954 & 0.03356 & 0.04319 & 0.03789 & 0.05092 & 0.05375 & 0.06450 \\
\hline$V R_{C H \_W D, 1}$ & $11.01 \%$ & $9.29 \%$ & $10.41 \%$ & $12.38 \%$ & $6.14 \%$ & $10.02 \%$ & $16.82 \%$ \\
\hline$\sigma_{C H, 2}^{2}$ & 0.03073 & 0.03420 & 0.04572 & 0.04070 & 0.05234 & 0.05584 & 0.07223 \\
\hline$V R_{C H \_W D, 2}$ & $7.45 \%$ & $7.54 \%$ & $5.16 \%$ & $5.88 \%$ & $3.50 \%$ & $6.53 \%$ & $6.84 \%$ \\
\hline$U_{W D}$ & -0.00267 & -0.00349 & -0.00469 & -0.00197 & -0.00349 & -0.00756 & -0.00540 \\
\hline$U_{C H, 1}$ & -0.00184 & -0.00244 & -0.00340 & -0.00138 & -0.00277 & -0.00547 & -0.00366 \\
\hline$U I_{C H_{-} W D, 1}$ & 0.00084 & 0.00105 & 0.00128 & 0.00059 & 0.00072 & 0.00209 & 0.00174 \\
\hline$U_{C H, 2}$ & -0.00178 & -0.00236 & -0.00364 & -0.00140 & -0.00255 & -0.00572 & -0.00445 \\
\hline$U I_{C H_{-} W D, 2}$ & 0.00089 & 0.00113 & 0.00105 & 0.00058 & 0.00094 & 0.00184 & 0.00095 \\
\hline \multicolumn{8}{|c|}{ Panel B: Out-of-Sample Performance } \\
\hline$\sigma_{W D}^{2}$ & 0.03626 & 0.04147 & 0.04874 & 0.04928 & 0.06802 & 0.05950 & 0.08168 \\
\hline$\sigma_{C H, 1}^{2}$ & 0.03268 & 0.03796 & 0.04313 & 0.04328 & 0.06362 & 0.05309 & 0.06682 \\
\hline$V R_{C H \_W D, 1}$ & $9.87 \%$ & $8.47 \%$ & $11.49 \%$ & $12.02 \%$ & $6.29 \%$ & $10.75 \%$ & $18.19 \%$ \\
\hline$\sigma_{C H, 2}^{2}$ & 0.03455 & 0.03918 & 0.04604 & 0.04714 & 0.06597 & 0.05566 & 0.07509 \\
\hline$V R_{C H \_W D, 2}$ & $4.80 \%$ & $5.62 \%$ & $5.54 \%$ & $4.31 \%$ & $3.00 \%$ & $6.45 \%$ & $8.06 \%$ \\
\hline$U_{W D}$ & -0.00365 & -0.00468 & -0.00499 & -0.00365 & -0.00669 & -0.00737 & -0.00685 \\
\hline$U_{C H, 1}$ & -0.00241 & -0.00307 & -0.00348 & -0.00230 & -0.00456 & -0.00513 & -0.00456 \\
\hline$U I_{C H \_W D, 1}$ & 0.00124 & 0.00161 & 0.00151 & 0.00135 & 0.00213 & 0.00224 & 0.00229 \\
\hline$U_{C H, 2}$ & -0.00272 & -0.00340 & -0.00389 & -0.00275 & -0.00505 & -0.00555 & -0.00565 \\
\hline$U I_{C H \_W D, 2}$ & 0.00093 & 0.00127 & 0.00110 & 0.00090 & 0.00163 & 0.00182 & 0.00121 \\
\hline
\end{tabular}

${ }^{26}$ Details of the freight rate weights of cross hedge portfolios are presented in Section 2.2.

${ }^{27}$ Following a comment by a reviewer, we have replicated the cross hedge analysis again with only dry bulk and tanker futures contracts (without including container futures). The results suggest that for several scenarios, including container futures yields higher variance reductions, which is consistent with the view that including this segment adds value to the strategy. 
Notes: $\sigma_{C H, 1}^{2}\left(U_{C H, 1}\right)$ and $\sigma_{C H, 2}^{2}\left(U_{C H, 2}\right)$ are the variances (utilities) of the near-month and second near-month returns of cross hedge portfolios, respectively. $V R_{C H_{-} W D, 1}\left(U I_{C H_{-} W D, 1}\right)$ and $V R_{C H_{-} W D, 2}\left(U I_{C H_{-} W D, 2}\right)$ are the $V R$ and $U I$ of cross hedge over and above the well-diversified portfolio. See notes of Table 3 for the definitions of other variables.

A comparative analysis of the cross hedge and the direct hedge portfolios is also performed, based on the $V R$ and $U I$ criteria calculated from Equations (21) and (22), respectively. The weights of the physical freight rates in both portfolios are the same as in the well-diversified portfolio of freight rates, as shown in Constraints C and D (in Section 2.2). In-sample and outof-sample tests are presented in Table 7, indicating that the cross hedge portfolio marginally outperforms the direct hedge portfolio by reducing the variance of the portfolio up to $1.96 \%$ (for in sample analysis in Scenario 1).

Table 7. Cross Hedge vs. Direct Hedge Portfolio Performance

\begin{tabular}{|c|c|c|c|c|c|c|c|}
\hline & $\begin{array}{l}\text { Base } \\
\text { Scenario }\end{array}$ & Scenario 1 & Scenario 2 & Scenario 3 & Scenario 4 & Scenario 5 & Scenario 6 \\
\hline \multicolumn{8}{|c|}{ Panel A: In-Sample Performance } \\
\hline$\overline{\sigma_{D H, 1}^{2}}$ & 0.02978 & 0.03395 & 0.04335 & 0.03793 & 0.05135 & 0.05379 & 0.06497 \\
\hline$\sigma_{C H, 1}^{2}$ & 0.02954 & 0.03356 & 0.04319 & 0.03789 & 0.05092 & 0.05375 & 0.06450 \\
\hline$V R_{C H \_D H, 1}$ & $0.78 \%$ & $1.15 \%$ & $0.38 \%$ & $0.11 \%$ & $0.84 \%$ & $0.06 \%$ & $0.73 \%$ \\
\hline$\sigma_{D H, 2}^{2}$ & 0.03114 & 0.03489 & 0.04581 & 0.04088 & 0.05308 & 0.05600 & 0.07259 \\
\hline$\sigma_{C H, 2}^{2}$ & 0.03073 & 0.03420 & 0.04572 & 0.04070 & 0.05234 & 0.05584 & 0.07223 \\
\hline$V R_{C H \_D H, 2}$ & $1.34 \%$ & $1.96 \%$ & $0.19 \%$ & $0.45 \%$ & $1.39 \%$ & $0.28 \%$ & $0.49 \%$ \\
\hline$U_{D H, 1}$ & -0.00185 & -0.00247 & -0.00338 & -0.00145 & -0.00295 & -0.00546 & -0.00375 \\
\hline$U_{C H, 1}$ & -0.00184 & -0.00244 & -0.00340 & -0.00138 & -0.00277 & -0.00547 & -0.00366 \\
\hline$U I_{C H \_D H, 1}$ & 0.00001 & 0.00003 & -0.00002 & 0.00007 & 0.00019 & -0.00001 & 0.00009 \\
\hline$U_{D H, 2}$ & -0.00194 & -0.00261 & -0.00352 & -0.00168 & -0.00328 & -0.00573 & -0.00451 \\
\hline$U_{C H, 2}$ & -0.00178 & -0.00236 & -0.00364 & -0.00140 & -0.00255 & -0.00572 & -0.00445 \\
\hline$U I_{C H \_D H, 2}$ & 0.00016 & 0.00025 & -0.00012 & 0.00029 & 0.00073 & 0.00002 & 0.00005 \\
\hline \multicolumn{8}{|c|}{ Panel B: Out-of-Sample Performance } \\
\hline$\sigma_{D H, 1}^{2}$ & 0.03281 & 0.03813 & 0.04324 & 0.04343 & 0.06390 & 0.05311 & 0.06736 \\
\hline$\sigma_{C H, 1}^{2}$ & 0.03268 & 0.03796 & 0.04313 & 0.04328 & 0.06362 & 0.05309 & 0.06682 \\
\hline$V R_{C_{-} D H, 1}$ & $0.41 \% *$ & $0.47 \% *$ & $0.25 \% *$ & $0.33 \% *$ & $0.42 \% *$ & $0.05 \% *$ & $0.81 \% *$ \\
\hline$\sigma_{D H, 2}^{2}$ & 0.03468 & 0.03932 & 0.04607 & 0.04719 & 0.06593 & 0.05573 & 0.07541 \\
\hline$\sigma_{C H, 2}^{2}$ & 0.03455 & 0.03918 & 0.04604 & 0.04714 & 0.06597 & 0.05566 & 0.07509 \\
\hline$V R_{C H \_D H, 2}$ & $0.88 \% *$ & $0.87 \% *$ & $0.14 \% *$ & $0.71 \% *$ & $0.63 \% *$ & $0.18 \% *$ & $0.60 \% *$ \\
\hline$U_{D H, 1}$ & -0.00231 & -0.00302 & -0.00346 & -0.00232 & -0.00482 & -0.00514 & -0.00466 \\
\hline$U_{C H, 1}$ & -0.00241 & -0.00307 & -0.00348 & -0.00230 & -0.00456 & -0.00513 & -0.00456 \\
\hline$U I_{C H B H, 1}$ & -0.00011 & -0.00005 & -0.00002 & 0.00002 & 0.00026 & 0.00001 & 0.00009 \\
\hline$U_{D H, 2}$ & -0.00261 & -0.00335 & -0.00378 & -0.00287 & -0.00554 & -0.00556 & -0.00574 \\
\hline$U_{C H, 2}$ & -0.00272 & -0.00340 & -0.00389 & -0.00275 & -0.00505 & -0.00555 & -0.00565 \\
\hline$U I_{C H B H, 2}$ & -0.00009 & -0.00005 & -0.00019 & 0.00001 & 0.00022 & -0.00028 & 0.00014 \\
\hline
\end{tabular}

Notes: $V R_{C H_{-} D H, 1}\left(U I_{C_{-} D H, 1}\right)$ and $V R_{C H_{-} D H, 2}\left(U I_{C H_{-} D H, 2}\right)$ are the $V R$ (and $\left.U I\right)$ of the cross hedge over and above the direct hedge portfolio, respectively. See notes of Tables 5 and 6 for the definitions of the other variables. * denotes significance at 99\% level for out-of-sample $V R$. 
The out-of-sample $V R$ of cross hedge over and above the direct hedge is found to be statistically significant at the $99 \%$ level. This indicates that, the marginal benefit of cross hedge with the usage of futures contracts are observed over direct hedge. Moreover, the cross hedge portfolio performs relatively better for second near-month futures contracts compared to near-month futures contracts. Second near-month futures contracts produce a further $V R$ of as high as $1.96 \%$ $(0.88 \%)$, whereas near-month futures contracts produce the highest $V R$ of $1.15 \%(0.81 \%)$ insample (out-of-sample).

\section{Conclusion}

This study develops for the first time a new portfolio approach combining the physical diversification of freight rates and the financial hedging of freight derivatives, in three major sub-sectors (container, tanker and dry bulk) of the international shipping industry. It is also the first to provide insights on the hedging performance of the recently developed container futures market, with the underlying container segment of the shipping industry corresponding up to $60 \%$ of the overall value of goods transported by sea. The examination of container freight derivatives becomes relevant given the emerging nature of this market, potentially making corporate owners and operators reluctant to utilise it for hedging their freight rate exposures. This is reflected in its relatively low liquidity which in turn leads to inferior hedging effectiveness of the container freight futures contracts relative to more mature shipping futures markets (dry bulk and tanker). Results point to a decrease in freight rate risk up to $48 \%$ by holding a diversified portfolio of freight rates, and an additional decrease of up to $8 \%$ by hedging freight rate risk with futures contracts. This study highlights that practitioners can realise additional benefits (minimising their risk exposure) by holding freight futures contracts together with holding a well-diversified portfolio of freight rates. Results can also can act as a yardstick for researchers to gain a better understanding of the correlations between freight futures and underlying freight rate markets, and thus, help improve hedging strategies. The findings have important implications for overall business, commercial, and hedging strategies in the shipping industry, and can encourage the trading of freight futures contracts, which can potentially lead to improvements in freight futures markets' liquidity.

\section{Acknowledgements}

The authors would like to thank the Editor-in-Chief, the Guest Editor and two anonymous reviewers for their valuable comments on an earlier version of the study, as well as the LCH.Clearnet, the Baltic Exchange and Clarksons Shipping Intelligence Network for providing the data. The responsibility for any remaining errors rests fully with the authors. 


\section{REFERENCES}

ADLAND, R. \& HAIYING, J. 2017. Simulating physical basis risks in the Capesize freight market. Maritime Economics and Logistics, 19(2), 196-210.

ALEXANDRIDIS, G., SAHOO, S. \& VISVIKIS, I. 2017. Economic information transmissions and liquidity between shipping markets: New evidence from freight derivatives. Transportation Research Part E: Logistics and Transportation Review, 98, 82-104.

ALIZADEH, A. H., HUANG, C.-Y. \& VAN DELLEN, S. 2015a. A regime switching approach for hedging tanker shipping freight rates. Energy Economics, 49, 44-59.

ALIZADEH, A. H., KAPPOU, K., TSOUKNIDIS, D. \& VISVIKIS, I. 2015b. Liquidity effects and FFA returns in the international shipping derivatives market. Transportation Research Part E: Logistics and Transportation Review, 76, 58-75.

ALIZADEH, A. AND NOMIKOS, N., 2009. Shipping derivatives and risk management. Springer.

BERA, A. K., GARCIA, P. \& ROH, J.-S. 1997. Estimation of time-varying hedge ratios for corn and soybeans: BGARCH and random coefficient approaches. Sankhyā: The Indian Journal of Statistics, Series B, 346-368.

BERTSEKAS, D.P., NEDI, A. and OZDAGLAR, A.E., 2003. Convex analysis and optimization.

BOLLERSLEV, T. 1987. A conditionally heteroskedastic time series model for speculative prices and rates of return. The review of economics and statistics, 542-547.

BRENNAN, M. J., SCHWARTZ, E. S. \& LAGNADO, R. 1997. Strategic asset allocation. Journal of Economic Dynamics and Control, 21, 1377-1403.

CASS, D. \& STIGLITZ, J. E. 1970. The structure of investor preferences and asset returns, and separability in portfolio allocation: A contribution to the pure theory of mutual funds. Journal of Economic Theory, 2, 122-160.

CULLINANE, K. 1995. A portfolio analysis of market investments in dry bulk shipping. Transportation Research Part B: Methodological, 29, 181-200.

DICKEY, D. A. \& FULLER, W. A. 1981. Likelihood ratio statistics for autoregressive time series with a unit root. Econometrica: Journal of the Econometric Society, 1057-1072.

EDERINGTON, L. H. 1979. The hedging performance of the new futures markets. The Journal of Finance, 34, 157-170.

ENGLE, R. F. \& GRANGER, C. W. 1987. Co-integration and error correction: representation, estimation, and testing. Econometrica: journal of the Econometric Society, 251-276.

ENGLE, R. F. \& KRONER, K. F. 1995. Multivariate simultaneous generalized ARCH. Econometric theory, 11, 122-150.

FIGLEWSKI, S. 1984. Hedging performance and basis risk in stock index futures. The Journal of Finance, 39, 657-669.

FIGLEWSKI, S. 1985. Hedging with stock index futures: theory and application in a new market. Journal of Futures Markets, 5, 183-199.

FRANCKLE, C. T. 1980. The hedging performance of the new futures markets: Comment. The Journal of Finance, 35, 1273-1279.

GOULAS, L. \& SKIADOPOULOS, G. 2012. Are freight futures markets efficient? Evidence from IMAREX. International Journal of Forecasting, 28(3), 644-659.

JOHANSEN, S. 1988. Statistical analysis of cointegration vectors. Journal of economic dynamics and control, 12, 231-254.

JOHNSON, L. L. 1960. The theory of hedging and speculation in commodity futures. The Review of Economic Studies, 27, 139-151. 
KAVUSSANOS, M. \& VISVIKIS, I. 2004. The hedging performance of over-the-counter forward shipping freight markets. Conference Proceedings, 14th International Association of Maritime Economists (IAME) Conference, Izmir, 30.

KAVUSSANOS, M. G. \& NOMIKOS, N. K. 2000a. Constant vs. time-varying hedge ratios and hedging efficiency in the BIFFEX market. Transportation Research Part E: Logistics and Transportation Review, 36, 229-248.

KAVUSSANOS, M. G. \& NOMIKOS, N. K. 2000b. Futures hedging when the structure of the underlying asset changes: The case of the BIFFEX contract. Journal of Futures Markets, 20, 775-801.

KAVUSSANOS, M. G. \& NOMIKOS, N. K. 2000c. Hedging in the freight futures market. The Journal of Derivatives, 8, 41-58.

KAVUSSANOS, M. G. \& VISVIKIS, I. D. 2010. The hedging performance of the Capesize forward freight market. Eds.) Cullinane, K., The International Handbook of Maritime Economics and Business, Edward Elgar Publishing.

KRONER, K. F. \& SULTAN, J. 1993. Time-varying distributions and dynamic hedging with foreign currency futures. Journal of financial and quantitative analysis, 28, 535-551.

LEVY, H. \& MARKOWITZ, H. M. 1979. Approximating expected utility by a function of mean and variance. The American Economic Review, 69, 308-317.

LI, K. X., QI, G., SHI, W., YANG, Z., BANG, H.-S., WOO, S.-H. \& YIP, T. L. 2014. Spillover effects and dynamic correlations between spot and forward tanker freight markets. Maritime Policy \& Management, 41, 683-696.

LINDAHL, M. 1992. Minimum variance hedge ratios for stock index futures: duration and expiration effects. Journal of Futures Markets, 12, 33-53.

MARKOWITZ, H. 1952. Portfolio selection. The Journal of Finance, 7, 77-91.

MARKOWITZ, H. M. 1968. Portfolio selection: efficient diversification of investments, Yale university press.

MCNEW, K. P. \& FACKLER, P. L. 1994. Nonconstant optimal hedge ratio estimation and nested hypotheses tests. Journal of Futures Markets, 14, 619-635.

PARK, T. H. \& SWITZER, L. N. 1995. Bivariate GARCH estimation of the optimal hedge ratios for stock index futures: a note. Journal of Futures Markets, 15, 61-67.

PHILLIPS, P. C. \& PERRON, P. 1988. Testing for a unit root in time series regression. Biometrika, 335-346.

ROQUES, F. A., NEWBERY, D. M. \& NUTTALL, W. J. 2008. Fuel mix diversification incentives in liberalized electricity markets: A Mean-Variance Portfolio theory approach. Energy Economics, 30, 1831-1849.

SHARPE, W. F. 1994. The sharpe ratio. The journal of portfolio management, 21, 49-58.

STEIN, J. L. 1961. The simultaneous determination of spot and futures prices. The American Economic Review, 51, 1012-1025.

THUONG, L. T. \& VISSCHER, S. L. 1990. The Hedging Effectiveness of Dry-Bulk Freight Rate Futures. Transportation Journal, 29, 58-65.

TSAI, M.-T., SAPHORES, J.-D. \& REGAN, A. 2011. Valuation of freight transportation contracts under uncertainty. Transportation Research Part E: Logistics and Transportation Review, 47, 920-932.

TSOUKNIDIS, D. A. 2016. Dynamic volatility spillovers across shipping freight markets. Transportation Research Part E: Logistics and Transportation Review, 91, 90-111.

TUY, H., HOANG, T., Hoang, T., MATHÉMATICIEN, V.N., HOANG, T. and MATHEMATICIAN, V., 1998. Convex analysis and global optimization (p. 22). Dordrecht: Kluwer. 